University of Nebraska - Lincoln

DigitalCommons@University of Nebraska - Lincoln

Educational Psychology Papers and

Publications

Educational Psychology, Department of

1996

Issues in the Treatment of Depressed Children

\author{
Kevin D. Stark \\ University of Texas at Austin \\ Scott A. Napolitano \\ University of Nebraska-Lincoln, snapolitano2@unl.edu \\ Susan M. Swearer Napolitano \\ University of Nebraska-Lincoln, sswearernapolitano1@unl.edu \\ Kristen Schmidt \\ University of Texas at Austin \\ Deborah Jaramillo \\ University of Texas at Austin \\ See next page for additional authors
}

Follow this and additional works at: https://digitalcommons.unl.edu/edpsychpapers

Part of the Educational Psychology Commons

Stark, Kevin D.; Napolitano, Scott A.; Swearer Napolitano, Susan M.; Schmidt, Kristen; Jaramillo, Deborah; and Hoyle, Jonathan, "Issues in the Treatment of Depressed Children" (1996). Educational Psychology Papers and Publications. 136.

https://digitalcommons.unl.edu/edpsychpapers/136

This Article is brought to you for free and open access by the Educational Psychology, Department of at DigitalCommons@University of Nebraska - Lincoln. It has been accepted for inclusion in Educational Psychology Papers and Publications by an authorized administrator of DigitalCommons@University of Nebraska - Lincoln. 


\section{Authors}

Kevin D. Stark, Scott A. Napolitano, Susan M. Swearer Napolitano, Kristen Schmidt, Deborah Jaramillo, and Jonathan Hoyle 


\title{
Issues in the treatment of depressed children
}

\author{
KEVIN D. STARK, SCOTT NAPOLITANO, SUSAN SWEARER, KRISTEN SCHMIDT, \\ DEBORAH JARAMILLO, AND JONATHAN HOYLE
}

University of Texas

\begin{abstract}
Basic research into the cognitive, behavioral, familial, and physiological disturbances associated with depressive disorders during childhood is reviewed. Implications for the development of a treatment program are discussed and a comprehensive treatment model is proposed. The proposed model includes intervention strategies for the child, parents, family, and school. The child component consists of intervention strategies for the affective, cognitive, behavioral, and physiological disturbances that are evident from the existing research. The parent training component is designed to address disturbances in parenting due to cognitive disturbances and skills deficits. The family therapy component emphasizes changing interaction patterns that communicate schema-consistent maladaptive interactions. A school consultation component is proposed in which school personnel support the skills training through prompting use of the skills and reinforcement of the use of the coping skills.
\end{abstract}

Key words: Childhood depression, Treatment of childhood depression

Depressive disorders during childhood appear to be more common and of longer duration than previously thought. Onset of a depressive disorder during childhood is a risk factor for later episodes, impacts the youngster's psychosocial functioning, family system, and parent-child dyads, and has potentially life-threatening consequences. Perhaps because of a recognition of the seriousness of the disorder and the growing number of youths affected by it, research in the area has mushroomed over the past 15 years. As more is learned about the disorder, more issues become evident. Numerous advances have been made in many areas including: our understanding of the nature of the disorder, its impact on the youngster and his or her family, its course, common co-occurring disturbances, and how to assess it. However, issues surrounding the treatment of depressed children have been sorely neglected and few developmentally sensitive treatment models have been proposed. Consequently, although a breadth of information will be reviewed, the focus will be on integrating this information to highlight its treatment implications and on a proposed treatment model.

When trying to develop an effective intervention for depressed youths, the most fundamental question that needs to be addressed is the etiology of depressive disorders during childhood. If it is possible to identify etiologic variables and disturbances that are associated with the disorder, it may be

Address correspondence and reprint requests to: Kevin D. Stark, University of Texas, Department of Educational Psychology, Sanchez Building Room 504, Austin, TX 78712. possible to develop an intervention package that addresses each of the disturbances. This belief provides the structure around which this review was written. Information was included to provide an understanding of the disturbances associated with depressive disorders during childhood and that has implications for models of the etiology and treatment of depressive disorders. Both psychosocial and biological factors play a crucial role in the development and maintenance of depressive disorders. Research and theory regarding the major psychosocial risk factors including disturbances in cognition, behavior, and the family environment are discussed along with a brief discussion of biological factors. This is followed by a discussion of implications for the development of a treatment program. A treatment model is proposed and issues in the treatment of depressed youths are discussed. To provide a context within which to consider the discussion, the review first turns to a description of existing treatment outcome research.

\section{Treatment Outcome Studies}

\section{Pharmacological Interventions}

"While virtually all the antidepressant and mood stabilizing drugs found useful in the treatment of adults have been tested with children, systematic studies with results that can confidently be applied by child psychiatrists are rare" (Rancurello, 1985, p. 88). The most common drugs for treating depression in children are the tricyclic antidepressants, of which imipramine, amitriptyline, and nortriptyline are the 
most popular. The specific mechanisms of action are unclear, but it is thought that tricyclics block the reuptake of norepinephrine and serotonin by the presynaptic terminal (Julien, 1988). Conclusions regarding the effectiveness of the tricyclics for children are mixed. Initial controlled studies indicated no difference between imipramine and placebos. In open-trial studies some encouraging findings have been reported for the effectiveness of tricyclic antidepressants with depressed children and adolescents. In a study of 34 adolescents with diagnoses of major depression, $44 \%$ responded favorably to imipramine (Ryan et al., 1986). A higher response rate $(75 \%)$ was reported for children in a study of the effectiveness of nortriptyline (Geller, Perel, Knitter, Lycaki, \& Farvok, 1983). While these results are encouraging, they must be viewed in the light of the shortcomings of open-trial methodology. In particular, there is no control for placebo effects or demand characteristics. Results of investigations that control for these limitations by using the double-blind methodology to evaluate the effectiveness of tricyclic antidepressants do not indicate that antidepressants are any more effective than are placebos (Kashani, Shekim, \& Reid, 1984; Kramer \& Feiguine, 1981; Preskorn, Weller, Hughes, Weller, \& Bolte, 1987; PuigAntich et al., 1987). In an evaluation of one of the new generation of antidepressants (fluoxetine-Prozac) with adolescents, Simeon, Dinicola, Ferguson, and Coping (1990) did not find conclusive evidence to support the effectiveness of this pharmacological treatment for depression.

Unlike the adult literature, there have not been any studies in which the relative effectiveness of antidepressants, psychotherapy, and the combination of these two forms of therapy have been compared. Nonetheless, in a unique, but not methodologically rigorous study, Robins, Alessi and Colfer (1989) reported that 18 of 38 adolescents who received a diagnosis of major depression responded favorably to 6 weeks of psychotherapy. Of the 15 nonresponders who continued in the study, 12 responded to a combination of continued psychotherapy and a tricyclic medication (in one case lithium was added). These findings suggest there is mixed evidence, at best, to support the effectiveness of antidepressant medication for youths. Given the very widespread use of the new family of antidepressants (Prozac, Zoloft, Paxsil, Welbutrin) with children and adolescents, further research of their effectiveness relative to the tricyclics is warranted.

\section{Psychosocial Interventions}

To date, surprisingly little treatment outcome research has been reported with depressed youths. Clearly, a need for additional treatment outcome research exists. Perhaps the place to begin this endeavor would be to use single-subject designs so that more clinically realistic and individually tailored interventions can be designed. Only a few empirically evaluated case studies have been completed. Petti, Bornstein, Delamater, and Conners (1980) used a multimodal intervention with a 10 -year-old girl who had been hospi- talized for a chronic depressive disorder. The intervention consisted of individual (both psychological and pharmacological), group, and family therapy. During the initial phase of treatment, the therapeutic relationship was used to enhance self-esteem and to help her resolve some issues surrounding her parents. She also received remedial education to help her overcome academic deficiencies. A creative drama group was used to improve her interpersonal behavior. Concurrently she participated in family therapy. Because this first phase of treatment did not produce the desired improvements, she was placed on imipramine, which reduced her overt and subjective manifestations of depression. During the final phase of treatment, she participated in social skills training that produced an increase in eye contact, frequency and duration of smiles, duration of speech, and assertiveness. Frame, Matson, Sonis, Fialkov, and Kazdin (1982) evaluated the effectiveness of a skills training program that consisted of instruction, modeling, rehearsal, and feedback. This program was directed toward and led to an improvement in eye contact, volume and amount of speech, facial expressions, and body position.

A few control group, treatment outcome studies have been completed. Butler, Miezitis, Friedman, and Cole (1980) evaluated the relative effectiveness of a "roleplaying" treatment, "cognitive restructuring," attention placebo, and waiting list conditions for fifth- and sixth-grade students. The intervention programs were administered in small groups during ten 1-hr weekly meetings. Results indicated that the greatest improvement in the subjective experience of depressive symptoms was reported by subjects in the role-playing condition. These youngsters were taught social skills, they were sensitized to their thoughts and feelings as well as those of others, and they were taught to generate alternative solutions when facing stressful situations. These skills were acquired through role playing followed by feedback and applied through homework assignments. Children in the cognitive restructuring condition were taught listening skills, the relationship between thoughts and feelings, and to identify and change maladaptive thoughts. The investigators noted that the children were not as engaged by this intervention.

Stark, Reynolds, and Kaslow (1987) compared the relative effectiveness of self-control and behavioral treatments to a waiting list condition. The treatments were conducted in twelve 45-50-min group sessions. The self-control treatment was designed to teach the youngsters more adaptive skills for self-monitoring, self-evaluation, attributing the causes of good and bad outcomes, and self-consequating. The skills were applied through homework assignments. The behavioral treatment consisted of education about feelings and interpersonal behavior, and a combination of training in problem-solving skills, self-monitoring of pleasant events, activity scheduling, and social skills training. Once again, the skills were applied through homework assignments. Results of the study indicated that children in both 
treatments reported a significant reduction in depression as assessed through the Child Depression Inventory (CDI) and a semistructured clinical interview. Also, both groups reported significantly less depression than children in the waiting list control condition. Subjects in the latter condition reported minimal change. The improvements were clinically as well as statistically significant, and they were maintained at a 5-week follow-up.

Results of this initial study were encouraging and led to a second study with a more seriously impaired sample of children from Grades 4-7. In this study, an expanded cognitive-behavioral treatment was compared to a traditional counseling condition that emphasized activities designed to enhance self-esteem. Participants met in groups of four with a pair of graduate student therapists. The groups met for 24 to 26 sessions lasting $45-50$ min during a 3.5month period. Meetings were held twice weekly for 8 weeks and once a week thereafter. In addition to group meetings, monthly meetings were held with the youngsters' families.

The cognitive-behavioral treatment included training in self-control skills, social and assertiveness skills, cognitive restructuring, and problem solving. The objective of the family meetings was to get the parents to encourage their children to use their coping skills and to engage in more pleasant activities as a family. In the traditional counseling condition, the group interactions, discussions, and suggestions served as the therapeutic vehicle. In addition, during each session the children completed an exercise that either helped them learn more about emotions or enhance selfesteem. The therapists behaved in an empathic and nondirective fashion. The objective of the family sessions was to improve communication and increase the family's involvement in pleasant activities.

Results indicated that both treatments were effective at reducing severity of depressive symptoms as assessed with a self-report measure and the Schedule for Affective Disorders and Schizophrenia (K-SADS) interview. However, subjects in the cognitive-behavioral condition reported significantly more improvement on the interview and on a measure of depressive cognitions. Improvements were maintained at 7-month follow-up.

Reynolds and Coats (1986) evaluated the relative efficacy of a cognitive-behavioral treatment and a relaxation training condition to a waiting list control condition. The cognitive-behavioral treatment consisted of a combination of training in self-control and behavioral skills. The relaxation treatment consisted of training in progressive muscle relaxation as a coping skill when confronted with stress. Results indicated that both treatments were effective at reducing depression as measured by a self-report questionnaire and clinical interview. These improvements were maintained at a 5-week follow-up.

Lewinsohn, Clarke, Hops, Andrews, and Williams (1990) compared the relative effectiveness of a cognitive-behavioral treatment with and without a parent training compo- nent. Adolescent participants met for $2 \mathrm{hr}$ in groups twice a week for 7 weeks. Parents of some of the adolescents also met in groups for seven weekly 2 -hr meetings. Parents were taught negotiation and conflict resolution skills during their meetings. Results indicated that adolescents in both treatments improved significantly on self-report and interview measures of depression relative to pretreatment assessment and the waiting list subjects. There were no significant differences between the two active treatments. Parents who participated in the training, relative to parents whose children were the only participants and to waiting list control parents, reported significantly fewer behavior problems with their children at post-treatment. At a 24-month followup, subjects in both active treatments reported continued improvement.

In another study of group therapy for depressed adolescents, Fine, Forth, Gilbert, and Haley (1990) compared social skills training to a therapeutic support group therapy. Both groups met one time per week for 12 weeks. Results indicate that both forms of group therapy were equally effective in treating clinically depressed adolescents over time. Immediately following treatment, subjects in the therapeutic support groups demonstrated significantly greater reductions in depressive symptoms as well as significantly greater increases in self-concept. These treatment gains were maintained at a 9-month follow-up. While the adolescents in the social skills training groups demonstrated fewer reductions in depressive symptoms and fewer increases in self-concept immediately following treatment, by the 9-month follow-up, they demonstrated improvement in both of these areas that was equivalent to the subjects in the therapeutic support condition.

A study designed to test the acceptability and efficacy of interpersonal psychotherapy for depressed adolescents (IPT-A) was conducted by Mufson et al. (1994). On initial assessment, 12 adolescents had major depression, 1 adolescent met criteria for dysthymic disorder, and 1 met criteria for depressive disorder NOS. Following a 12-week treatment with IPT-A, none of the subjects met DSM-III-R criteria for any depressive disorder. There was also significant improvement in symptoms of psychological and physical distress as measured by the SCL-90. Statistically significant improvements in overall social functioning as measured by the SAS-SR were also demonstrated; however, the means on the SAS-SR suggest that the difference is not clinically significant due to the lack of range in the scores and the relatively high level of initial social functioning.

Overall, results of existing treatment outcome research are encouraging as a number of different psychosocial interventions have produced significant reductions in depressive symptoms. The diversity of effective interventions begs the question: What are the common core components that produce this change? An in depth discussion of these results and the methodological limitations and implications of the research can be found in Stark, Rouse, and Livingston 
(1991). Based on the results of our own treatment outcome research and the experience of running the groups, it is apparent that modifications are needed. This will be especially true as the interventions are applied to clinical populations that are more likely to be experiencing a comorbid condition, and to have a multiplicity of confounding difficulties including histories of physical and sexual abuse, familial substance abuse, and severe parental and familial psychopathology. To meet these challenges, the treatment programs must become more comprehensive in terms of the issues they address and the individuals who are the targets of intervention. Results of existing research can be used as a guide to the modification and further development of an effective treatment program for depressed youths.

\section{Cognitive, Behavioral, Family, and Physiological Disturbances}

The study of depressive disorders during childhood has often used research with adults for its starting point. In many ways, this has proven fruitful. Such an approach has allowed investigators to conduct research with children parallelling research that has demonstrated explanatory utility with adults. Much of this research with adults has been designed to evaluate theories or portions of models of depression. These adult models have served as guides to the study of depressive disorders during childhood. The adult treatment models also have been employed with depressed children.

Contemporary theories of adult depression conceptualize it as the "final common pathway" (Akiskal \& McKinney, 1975 ) for the reciprocal influence of cognitive, behavioral, contextual/interpersonal, and biochemical factors (Bedrosian, 1989; Hammen, 1991). The fit of this multifactorial approach seems promising for childhood variants of depressive disorders as well, and has direct implications for the development and implementation of effective interventions for depressed youths. Stark et al. (1991) have proposed a related model hypothesizing that the primary socializing agent for the child is his or her family, and that the child naturally develops essential intra- and interpersonal behaviors and cognitive processes within this interpersonal context. Furthermore, the interpersonal context maintains and is in turn influenced by, the child's skills and cognitive processes. In the following sections we briefly review research that evaluates the relationship between each of the four domains (cognitive, behavioral, familial, and biochemical) and depressive disorders during childhood.

\section{Cognitive Variables and Depression during Childhood}

The cognitive functioning of depressed youths has received a disproportionate amount of attention from researchers. This heightened interest probably stems from the fact that cognitive models have been the predominant models of depression in adults. Thus, given the similarity in the symptom picture of depression in children and adults, it has seemed logical, and helpful for theory building, that the same models could be applied to children. The models that have received the greatest empirical attention have been Beck's cognitive theory (e.g., Beck, 1967) and the learned helplessness/hopelessness model (Abramson, Seligman, \& Teasdale, 1978: Abramson, Metalsky, \& Alloy, 1988). Some of the major tenets of these models and results of relevant research will be discussed. However, prior to this discussion we turn to some related developmental concerns.

\section{Discussion of Developmental Applicability}

Many investigators have assumed that children's cognition is similar in form and can be assessed in the same fashion as cognition in adults. For example, it has been assumed that children, like adults, ask themselves why an event has occurred and that this cognition takes on the form of an attribution reflective of a more encompassing attributional style. Recently this assumption of developmental similarity has been empirically evaluated with mixed results. A study by Gotlib, Lewinsohn, Seeley, Rhode, and Redner (1993) conducted on adolescents provides support that, consistent with the adult literature, negative cognitions can be divided into two categories that assess different aspects of cognitive functioning (outlook and attributions). In contrast, using a normal adolescent population, Garber, Weiss and Shanley (1993) did not find a separation of cognition into outlooks and attributions. Their results identified one factor of negative cognitions that included both expectations and attributions. Thus, it is not yet clear from an empirical standpoint at what age children's cognitions assume the form of an attribution similar to that in adults.

Additional research has begun to apply developmental principles to the evaluation of cognitive theories of depression. Based on Piaget's theory of cognitive development, Moilanen (1993) hypothesized that children need to be at least to the formal operations stage of reasoning (12+ years), where they can think about the future and the hypothetical, before they can experience hopelessness and severe depression. However, results were contrary to this hypothesis as younger children who were in the concrete operations level actually were more depressed and experienced greater hopelessness than the children who had reached formal operations. Rholes, Blackwell, Jordan, and Walters (1980) investigated children's susceptibility to learned helplessness with the utilization of hidden figures problems with repeated success or failure feedback. It was hypothesized that younger children (kindergarten and first graders) would experience less helplessness than older children (third and fifth graders) due to developmental differences in causal attributions. This hypothesis was supported in that younger subjects showed no evidence of helplessness on the hidden figures tasks. However, the fifth-grade children who had failed appeared to be more helpless in both persistence and 
performance on the hidden figures than those who had succeeded. The authors concluded that this suggests that younger children are relatively less susceptible to learned helplessness, perhaps because they do not make the same types of attributions as older children when confronted with repeated failure. Consistent with this research and other research within developmental psychology, children begin to be able to make negative evaluations around 8 years of age, and it is at this age that their sense of self, future, and causality develop (Garber, 1992). Results of the research discussed in the following sections on the applicability of the cognitive models of depression must be considered within the context of the limited knowledge about important developmental differences in cognitive functioning of children and adolescents relative to each other and to adults.

\section{Overview of Major Cognitive Models}

The major cognitive theories of depression are stressdiathesis models in which the cognitive disturbance represents the diathesis and negative life events represent the stress. The cognitive disturbance moderates the effects of stress on depressive symptoms. In other words, cognitive variables are assumed to interact with negative life events to produce depression. In Beck's model (e.g., Beck, 1967), the cognitive disturbance stems from maladaptive schemata, which are hypothesized to be latent variables that are activated by related negative events. Once activated, the schemata filter and guide the processing of information in a negatively distorted fashion, which leads to information processing errors and a plethora of intrusive and believable (to the individual) negative cognitions. These cognitions produce the depressive symptoms. In a similar, although somewhat different vein, a depressogenic attributional style is assumed to mediate the impact of negative life events and depressive symptoms. In the learned helplessness/hopelessness model (Abramson et al., 1978, 1988), the individual who is prone to the development of depression is assumed to have a trait-like tendency to attribute the cause of negative events to internal, stable, and global causes and positive events to external, unstable, and specific causes. Attributional style is hypothesized to be a stable variable that serves as a filter for processing information.

Cole and Turner (1993) drew upon Baron and Kenny's (1986) distinction between moderational and mediational models and argued from a developmental perspective that the stress-diathesis models of adult depression are moderational (e.g., negative life events interact with cognitive disturbance to produce depression) in nature and thus less applicable to depressed children. They hypothesized that a mediational model is more applicable to children because the cognitive phenomena associated with depression are less stable due to the fact that they are still developing. Thus, within a mediational model, negative life events and/or negative competency feedback would impact cognition which would then lead to depressive symptoms. Results of an in- vestigation (Cole \& Turner, 1993) using a cross-sectional approach designed to evaluate moderational and mediational models of stressful events, negative competency feedback, cognitive errors, attributional style, and depressive symptoms supported a mediational model rather than a moderational model. In other words, cognitive errors and attributional style completely mediated the effect of competency feedback on depressive symptoms. The relationship between positive and negative life events and depressive symptoms was partially mediated by the cognitive variables. Life events had a direct effect on depressive symptoms, and an indirect effect on depressive symptoms through attributional style and cognitive errors. Minimal support was found for moderational models. Thus, cognitive disturbances were associated with depression, and these disturbances may reflect, or be related to, negative life events.

\section{Empirical Evaluation}

\section{Cognitive Theory of Depression}

The applicability of a number of the major tenets of Beck's model (e.g., Beck, 1967) have been evaluated for depressed children. Central to his model of depressive disorders is the notion that an individual's depressive symptoms are maintained by disturbances in cognition (Beck, 1976). Depressed individuals are hypothesized to experience a negative bias in their thoughts about the self, the world, and the future, which is referred to as the depressive cognitive triad. An association has been found between each component of the depressive cognitive triad and severity of depressive symptoms in children. Depressed children have lower self-esteem (e.g., Reynolds, Anderson, \& Bartell, 1985) and perceived competence (e.g., Asarnow \& Bates, 1988; Asarnow, Carlson, \& Guthrie, 1987; Blechman, McEnroe, Carella, \& Audette, 1986), feel more hopeless about their future (e.g., Benfield, Palmer, Pfefferbaum \& Stowe, 1988; Kazdin, Rodgers, \& Colbus, 1986) and experience more negative thoughts about their lives in general (e.g., the automatic thoughts studies). In one of our own investigations (Kaslow, Stark, Printz, Livingston, \& Tsai, 1992), results indicated that depressed children report a more negative view of self, world, and future than anxious and control children. However, no research has evaluated the potential role that the cognitive triad may play in the development of depressive disorders.

Another major tenet of Beck's cognitive theory of emotional disorders is the notion that each emotional disorder is characterized by a unique disturbance in cognition. In other words, the cognitions associated with depressive disorders should be different from those associated with, for example, anxiety disorders. This is referred to as the cognitive specificity hypothesis. Beck (1967) hypothesized that the cognitions associated with depressive disorders center around a theme of loss, while those associated with anxiety disorders are characterized by threat. A number of studies have been 
conducted that address this issue. Support for the cognitive specificity hypothesis has been found, although the relationship between loss and threat cognitions and depression and anxiety may be more complex than initially hypothesized. Garber et al. (1993) found partial support for the cognitive specificity hypothesis with depressed and anxious adolescents. Loss-related cognitions were correlated with depressive symptoms to a greater extent than they were to anxious symptoms. However, threat-related cognitions were correlated with both anxious and depressive symptoms to a similar extent. Thus, support was evident for the contentspecificity hypothesis only for depressive symptoms. Laurent and Stark (1993) evaluated the cognitive functioning of depressed, anxious, and comorbid depressed anxious children using a variety of measures. Results partially supported the cognitive specificity hypothesis. All three disturbed groups reported significantly more negative cognitions than did controls regardless of the content (loss vs. threat). However, when the valence of the cognitions was taken into account, that is, the results were analyzed separately for positive and negative cognitions, a significant difference became evident. Depressed youths reported significantly fewer positive cognitions than did anxious children, although there was no difference between the two groups in negative cognitions. The comorbid group reported significantly more negative cognitions and significantly fewer positive cognitions than did the anxious group. Thus, in this study the content of the thoughts did not differentiate depressed and anxious children, but the valence did.

Ambrose and Rholes (1993) hypothesized that the relationship between loss and threat cognitions and depressive and anxiety disorders was dependent on the intensity of the cognitions. More specifically, they hypothesized that loss cognitions would show a linear relationship to depressive symptoms but an inverted $U$ relationship to anxious symptoms. Threat cognitions would shift away from anxious symptoms to depressive symptoms at higher ranges. In other words, as the youngster felt more overwhelmed by the anxious thoughts, he or she would begin to show signs of depressive symptoms rather than anxious symptoms. Results of their investigation supported their major hypotheses. Loss cognitions had a stronger relationship to depressive symptoms than did threat cognitions, and threat cognitions had a stronger relationship to anxiety than loss cognitions. Furthermore, as the threat cognitions increased in severity, they became more associated with depressive symptoms and less associated with anxious symptoms. As loss cognitions increased, they became less associated with anxious symptoms and more associated with depressive symptoms, thus providing support for the cognitive specificity hypothesis, and further elaborating on the complex nature of the relationship that may exist between cognitions and child psychopathology.

The cognitive specificity hypothesis was tested in one other study (Gotlib et al., 1993), which was unique because the cognitions of depressed youths were compared to those of psychiatric controls compesed of youngsters with a variety of other psychiatric diagnoses. Also, unlike previous investigations, they evaluated the cognitive specificity hypothesis with a clinical sample. Based on previous research with adults and results of their own factor analyses, a variety of cognitive measures were grouped into two composite scores: (1) negative outlook, and (2) negative explanation. The negative outlook factor included items designed to assess dysfunctional attitudes, expectations for positive outcomes, self-reinforcement, self-esteem, and perceived control. The negative explanation factor comprised the items from the KASTAN Attributional Style Questionnaire for Children (Kaslow, Tanenbaum, \& Seligman, 1978). The depressed youths reported significantly more negative cognitions than did the psychiatric controls, but these two groups did not differ in terms of attributional style. Once again, these results suggest that the relationship between cognitions and psychopathology is not a simple one.

Another concept that is central to Beck's cognitive theory of depression is that of the self-schema. The self-schema comprises the individual's most central rules for life. The depressed individual is hypothesized to feel inadequate, unlovable, and unacceptable. The self-schema is presumed to facilitate encoding, storage, and retrieval of negative selfrelevant information and may account for such symptoms as selective attention to, and personalization of, salient negative events. Support for the existence of a self-schema, which may facilitate the processing of self-relevant information, was evident in an investigation using an incidental recall depth of processing task. Children recalled significantly more adjectives that were processed at the selfrelevant level than adjectives processed at an impersonal level (Sellstrom, 1988). While Beck hypothesized that a negative self-schema guides the information processing of depressed individuals, support for this contention with depressed youths has not been forthcoming. Rather, to date, research with children has indicated that nondepressed youths possess a positive self-schema that is lacking in depressed youngsters. Hammen and Zupan (1984) reported that nondisturbed controls relative to mildly depressed youngsters (as assessed with the CDI; Kovacs, 1981) recalled a significantly greater proportion of positive selfdescriptive adjectives suggesting that a positive self-schema was directing information processing. Similar results have been reported for at-risk children (Jaenicke et al., 1987) and youngsters who were currently experiencing a depressive episode or had experienced a depressive episode in the past (Zupan, Hammen, \& Jaenicke, 1987). These investigators also found evidence of a stronger negative self-schema among the depressed youngsters.

Recognizing that reaction time (efficiency and consolidation), recall (encoding and availability), and recognition (accessibility of stored information) measures may assess different aspects of information processing. Prieto and col- 
leagues (Prieto et al., 1992) used all three measures to evaluate the schematic functioning of psychiatric patients who reported depressive symptoms relative to those who did not. Preliminary analyses indicated that reaction time and incidental recall measures do in fact assess different aspects of information processing. The self-schemas of nonclinic nondepressed and clinic nondepressed youngsters were positive and much stronger than their negative self-schemas. In contrast, clinic youngsters who reported elevated depressive symptoms possessed more of a balance of positive and negative self-schemas. The authors concluded that the selfschema seems to affect the acquisition of new positive and/or negative information much more than it affected retrieval. Thus, it appears to guide selective attention, encoding, and retrieval.

According to cognitive theory, the negative self-schema and other maladaptive schemata are maintained through, and give rise to, errors in information processing that result in the depressed individual exhibiting a negatively biased distortion in active information processing. Support for this theoretical contention has been reported for youngsters with self-reported depressive symptoms (Haley, Fine, Marriage, Moretti, \& Freeman, 1985; Leitenberg, Yost, \& CarrolWilson, 1986). This stands in contrast to some early research with depressed youngsters where the investigators reported that children who reported elevated levels of depressive symptoms experienced a deficit in information processing (Schwartz, Friedman, Lindsay, \& Narrol, 1982). Results of a series of three investigations (Kendall, Stark, \& Adam, 1990) were consistent with cognitive theory and indicated that depressed youngsters suffered from a distortion in self-evaluative information processing and did not suffer from a deficit in active information processing.

\section{Learned Helplessness/Hopelessness Model}

As noted above, the central premise of the learned helplessness/hopelessness model of depression is that stress will interact with a stable negative attributional style to produce depression in some individuals. Results of early studies that evaluated the reformulated model of learned helplessness depression, while mixed, were generally supportive as children who self-reported symptoms of depression also reported a more depressogenic attributional style. Specifically, these children reported internal, stable, and global attributions for negative events and external, unstable and specific attributions for positive events; although, the results for the positive events were not as strong (Asarnow \& Bates, 1988; Kaslow, Rehm, Siegel, 1984; Seligman, Peterson, Kaslow, Tannenbaum, Alloy, \& Abramson, 1984). Recent research also provides support for the basic tenets of the model (Cole \& Turner, 1993; Garber et al., 1993; Tems, Stewart, Skinner, Hughes, \& Emslie, 1993).

Initial research in the area did not address the specificity of the negative attributional style to depressive disorders by including a psychiatric control group. In a recent study that addressed this issue, Cole and Turner (1993) reported that depressed youngsters did not differ from a group of youngsters with a variety of other psychiatric disorders. Thus, a negative attributional style was not specific to depressive disorders in this study but was nonspecific to psychopathology in general.

Recently, a number of investigators have attempted to conduct a more complete evaluation of the attributional model of depression by looking at the interaction of stress and attributional style as they predict depressive symptoms (Cole \& Turner, 1993; Dixon \& Ahrens, 1992; Hammen, Adrian, \& Hiroto, 1988; Nolen-Hoeksema, Girgus, \& Seligman, 1986). The results have varied. However, this may be due to the populations studied and the form of stress that was evaluated. A number of the investigations have used normal school children as their subjects, while others have used atrisk or clinical populations. Some investigators have assessed major life events as the stressor, while others have looked at daily hassles as the stressor.

Nolen-Hoeksema and her colleagues (1986) followed school children for a year to evaluate the interactive effect of stress and attributional style on depressive symptoms. Major life events, attributional style, and depressive symptoms were assessed five times producing four intervals. Results indicated that attributional style alone predicted change in depressive symptoms during two intervals. The stress attributional style interaction significantly predicted change in depressive symptoms in one of the other intervals, while it marginally predicted change in the other interval. Among at-risk populations, Dixon and Ahrens (1992) reported that attributional style did not predict depressive symptoms, but a measure of daily hassles did. The interaction of daily hassles and attributional style significantly increased the predictive power of depression scores. Secondary analyses revealed that the effect of stress on depression was greatest for those who had a negative attributional style. In a study that included children of depressed parents, the interaction effect of stress (major life events) and attributional style failed to predict depression 8.4 months later (Hammen et al., 1988).

\section{Development of Depressive Cognitive Style}

Results of the investigations discussed above indicate that a number of the cognitive variables are related to depression. The question becomes, how do these disturbances in cognition develop and how are they maintained? Beck (Beck, Rush, Shaw, \& Emery, 1979), as well as others (e.g., Freeman, 1986), hypothesized that depressive schemata are formed through early learning experiences, especially those within the family. Cole and Turner (1993) believed that repeated exposure to negative life events, stressors, or specific forms of pathogenic feedback to the child lead to the internalization of negative cognitions and the eventual development of dysfunctional schemata. In addition, they noted that at certain developmental periods youngsters ac- 
tively seek information from daily experiences and from their peers about their own competencies, which they use to construct their sense of self. Young (1991) hypothesized that maladaptive schemata could be the result of inadequate parenting or ongoing aversive experiences within the family milieu such as repeated criticism or rejection. From the social learning perspective (Bandura, 1977), it also is possible that cognitive disturbances could be learned vicariously through parental modeling. Similarly, Stark, Schmidt, Joiner, and Lux (in press-b) hypothesized that youngster's sense of self, world, and future could represent the internalization of messages, verbal and nonverbal, that he or she receives from interactions with parents. A study was conducted to evaluate the relationship between a negative view of the self, the world, and the future (depressive cognitive triad) and two possible mechanisms for their development including parentally communicated maladaptive messages and parental modeling of a depressogenic style of thinking (Stark et al., in press-b). Results indicated that children's cognitive triad ratings were highly predictive of the severity of their level of depressive symptoms.

Given this relationship, we tried to identify which parental variables were predictive of the children's cognitive triad. Partial support was found for a social learning perspective as mothers' cognitive triad ratings were significantly related to their children's cognitive triad ratings. Results also indicated that perceived parental messages predicted the children's level of depression. Consistent with our hypotheses, perceived parental messages communicated to the children about the self, the world, and the future were strongly predictive of the children's sense of self, world and future. Furthermore, the mediation analyses indicated that the effects of parental messages on the children's depression were completely, not partially, mediated by the child's view of self, world, and future. Perceived parental messages about the self, world, and future were predictive of the children's depression, but only as a function of their association with the children's sense of self, world, and future. Goodness of fit tests supported the model, which predicted that perceived parental messages predicted the children's cognitive triad predicting the children's level of depression. To rule out the competing hypothesis that the depression was causing the depressive cognitions that were leading to the perception of negative parental messages, we ran additional mediational analyses to test this hypothesis. Results of these analyses were not supportive of this competing model. Overall, preliminary support was found for two mechanisms that were hypothesized to be instrumental in the development of a depressogenic style of thinking.

\section{Implications and Treatment Issues}

Overall, there is support for an association between disturbances in cognitive functioning and depressive disorders during childhood. Furthermore, the disturbances appear to be parallel to those reported in the adult literature, suggest- ing that cognitive therapy might be useful for depressed children. However, to effectively intervene, it is necessary to identify and understand developmental differences in cognitive processing between children and adults. To address this concern, a multitude of issues remain to be answered about the cognitive functioning of depressed children (for a review, see Garber, 1992). A consensus is appearing that indicates that children's cognitive processes are adequately developed for experiencing depressive disorders by age 8 years. However, it is not known whether the cognitions assume different forms at different ages. Some investigators find the same two broad categories of cognitions, expectations and attributions, in youths and adults (Gotlib et al., 1993), while others have not found this (Garber et al., 1993). In a similar vein, it is not known whether new issues arise at different points during development. For example, Garber et al. (1993) reported an increase in egocentrism with age that could be a vulnerability factor. These youngsters are at increased risk for personalizing negative events. Likewise, they are likely to personalize undefined events. This suggests that an objective of treatment would be to help them become less self-focused. If additional developmental risk factors exist and they can be identified, they may guide the nature and direction of intervention. Another developmental consideration is the degree to which the stress-diathesis models of depression are appropriate for children. Unlike adults, disturbances in cognitive processes serve a mediational rather than moderational role in depressive disorders in children (Cole \& Turner, 1993). Stressful events and negative competency feedback affect cognition, which then affects depressive symptoms. Cole and Turner (1993) suggest that this mediational relationship may be due to the cognitive disturbances not having been in existence for long enough to have become structuralized. If this is true, does it mean that these disturbances in children are more amenable to change, or does it mean that if you intervene at this critical developmental period that the intervention should be directed toward the environmental disturbances that are leading to the dysfunctional cognitions? If the latter is the case, then when the environmental disturbance is altered in a healthy way, will changes in cognition naturally follow? At least, these findings point to the importance of evaluating the primary contexts within which the child lives, and they point to the importance of devising interventions for these environmental stressors. Thus, unlike cognitive therapy with adults, the individual is not the primary and sole source of intervention. Rather, interventions directed toward the environment and significant others in the environment are equally important.

As noted above, stressful events impact cognition and have a direct relationship to depression. It appears as though stressful events, perhaps daily hassles more than major life events (Dixon \& Ahrens, 1992), have a direct impact on a youngster and lead to emotional distress. With prolonged exposure, a depressive disorder eventually develops. These 
findings suggest that recurrent negative events lead to the perception that the world is a distressing place, life is full of pain, and that it will always be this way. These results suggest that it is critical to intervene in the youngster's environment to eliminate or reduce the sources of stress. However, it is not clear whether the most effective way to do this is to actually alter the environment or to enhance the youngster's coping skills for dealing with the distressing events, or both. If the hassles are of an interpersonal nature, then the intervention may be directed at the youngster's social skills or interpersonal environment. If the intervention is directed at the environment, then the youngster's teachers or other school personnel will need to be involved in the intervention.

A self-schema appears to guide the information processing of children. Relative to nondepressed youths, the selfschema of depressed youths is less positive (Hammen \& Zupan, 1984; Jaenicke et al., 1987; Zupan et al., 1987). Furthermore, this less positive self-schema affects the acquisition of new positive and negative information through selective attention, encoding and retrieval of information (Prieto et al., 1992). These results suggest that a goal of treatment is enhancement of the youngster's sense of self. A common strategy for altering this disturbance is to have the children self-monitor positive events (Stark et al., 1985). However, this may not have the desired effect, and it may be especially difficult to accomplish because the existing selfschema will be guiding information processing in a fashion that prevents the acquisition of schema-inconsistent information. Thus, positive information is likely to be overlooked. It may be necessary to train significant others within the child's environment to help the youngster with selfmonitoring and with processing the outcome on a daily basis. Depressed youths have a tendency to negatively distort self-evaluative information (Kendall et al., 1990), which further inhibits the individual's chances to acquire positive self-relevant information. Once again it may be necessary for school personnel and parents to become involved in the treatment process. While research indicates that depressed youths distort information processing, the specific errors have yet to be identified. Thus, the specific nature of the intervention is not yet clear. It is very likely that each youngster will possess a unique pattern of information processing errors and require a unique set of intervention strategies. Once again, no research has been directed toward the elucidation of the most effective strategies for altering information processing errors in children.

Research (Stark et al., in press-b) and theory (Beck et al., 1979; Young, 1991) suggest that the cognitive disturbance may develop as a result of negative messages the youngster receives from his or her parents (Stark et al., in press-b), stressful events and negative competency feedback (Cole \& Turner, 1993). Further research is needed to identify the mechanism for this. This once again highlights the importance of intervening with the child's family and school.
Both environments could be the source of negative messages, stressful events, and negative competency feedback.

While children might have cognitive disturbances that are similar to those of adults, and they may have the cognitive ability to reflect on these disturbances, do they have the same metacognitive ability as adults to be able to accurately identify, reflect upon, evaluate, and counter maladaptive cognitions? What is the best way to do this? Through traditional cognitive therapy procedures such as what's the evidence and alternative interpretation, or are behavioral experiments the preferred mode for producing meaningful change? Does the mix of cognitive, behavioral, and environmental interventions change with developmental level?

\section{Behavioral Variables and Depression during Childhood}

\section{Empirical/Theoretical Rationale}

Social behavior and peer acceptance are important aspects of children's lives and have been shown to affect later adjustment and happiness (DuPaul \& Eckert, 1994; Matson \& Ollendick, 1988). Children who are deficient in social skills have a high incidence of school maladjustment, childhood psychopathology, and mental health problems as adults (Gresham, 1989). Severe deficits in social skills may result in a lack of social support that may potentiate psychiatric problems (Peterson, 1991). In children, social competence has been identified as an important factor in reducing the risk of psychological problems (Garmezy \& Matsen, 1986) as well as in improved prognosis within psychiatric samples (Cohen, Kershner, \& Wehrspann, 1988).

Social skills deficits have been hypothesized to be a primary causal variable in the development of depression through the resulting loss of social reinforcement and disruption of close interpersonal relationships (Lewinsohn, 1975). According to Lewinsohn, deficits in social skills lead to a reduction in the amount of response-contingent positive reinforcement that the individual receives. Furthermore, it has been posited that depressed individuals elicit a corresponding pattern of rejection in others that reinforces the depression (Coyne, 1976). In other words, a vicious cycle is established where poor social skills lead to interpersonal rejection, which produces depression and social withdrawal. Depressive symptoms are aversive to others, which leads to further interpersonal rejection, which exacerbates the depression. Given the "magnitude and severity" of problems associated with deficits in social skills, Matson and Ollendick (1988) concluded that social skills deficits should be considered a major part of the underlying etiology of emotional, personality, and adjustment problems of children. In addition, these authors state that efforts at improving social skills deficits may have very beneficial preventative effects.

Research suggests that depressed youths experience interpersonal difficulties. Depressed children are less popular (Jacobsen, Lahey, \& Strauss, 1983; Lefkowitz \& Tesiny, 
1985; Strauss, Forehand, Frame, \& Smith, 1984), less liked (Blechman, et al., 1986; Faust, Baum, \& Forehand, 1985; Peterson, Mullins, \& Ridley-Johnson, 1985), and are rejected by peers (Kennedy, Spence, \& Hensley, 1989). Perhaps this is sensed by depressed youths and accounts for findings indicating that depressed youngsters engage in less social interaction (Kazdin, Esveldt-Dawson, Sherick, \& Colbus, 1985). Consistent with Coyne's hypothesis, depressed children elicit negative reactions from adults (Mullins, Peterson, Wonderlick, \& Reaven, 1986) and peers (Kennedy et al., 1989). Social skills deficits (Kennedy et al., 1989; Matson, Rotatori, \& Helsel, 1983) as well as disturbances in social cognition (Sacco \& Graves, 1984) may contribute to these interpersonal difficulties. Based on an integrative cognitive-behavioral model, it is believed that if a social skills disturbance exists, it stems from a lack of social skills knowledge and/or a performance deficit that is the result of cognitions and physiological arousal that interfere with enactment of appropriate social behavior (Stark, Linn, MacGuire, \& Kaslow, in press-a).

Results of one of our own investigations (Stark et al., in press-a) suggest that the social skills disturbance associated with depression may not be as straightforward as previously thought. Based on teachers' and children's ratings, depressed children with and without a comorbid anxiety disorder were described as exhibiting significantly fewer appropriate social skills relative to their nondepressed classmates. According to the children's self-ratings, depressed and comorbid depressed-anxious children experienced social skills disturbances with the comorbid group experiencing the most and most severe disturbances. The social behaviors of children with a depressive disorder were characterized by an angry, jealous, and withdrawn style of interacting with others. Comorbid depressed and anxious children displayed additional inappropriate aggressive behaviors.

The social skills deficits did not appear to be due to a lack of social skills knowledge. The disturbed children knew what was appropriate and inappropriate social behavior, but they did not enact appropriate behaviors. Relative to nondisturbed controls, children with a depressive disorder reported experiencing significantly more negative and significantly fewer positive cognitions in social situations. They also reported experiencing more aversive physical arousal in social situations.

\section{Implications and Treatment Issues}

Depressed children have interpersonal difficulties that lead to their being less popular (Jacobsen et al., 1983), less liked (Blechman et al., 1986), and rejected (Kennedy et al., 1989). They appear to experience a deficit in social skills that is characterized by an angry and withdrawn style of interacting with others (Stark et al., in press-a). The specific behaviors that comprise this style of interaction are not known. Research suggests that depressed youths know how to behave in a socially appropriate fashion but do not. This appears to be due to a combination of cognitive disturbance and the experience of aversive physical arousal in social situations (Stark et al., in press-a). Are the physical arousal and negative cognitions a reflection of a mood disturbance (anger) that is causing the angry and withdrawn behavior? While it appears as though social skills training may be an important component in a treatment for depressed youths, Kazdin's (1989) and Matson's (1989) belief that social skills training is an effective treatment for depressed children has not yet been empirically evaluated. Additional research directly designed to evaluate this contention is necessary. Furthermore, it would appear as though the social skills intervention should include treatment components that are directed at the cognitive, possible mood, and physical disturbances. Thus, cognitive restructuring, relaxation training, and other procedures designed to improve mood may have to be incorporated into the social skills training. Once again, parents and teachers may have to be included in the intervention. They can provide the youngster with encouragement for enactment of appropriate social behaviors through a reward program. In addition, they can provide the youngster with objective feedback about his or her social interactions, countering any distortions.

\section{Family Variables and Depression During Childhood}

\section{Genetic Influence}

There is compelling evidence to support a link between a genetic vulnerability and depressive disorders during childhood (Clarkin, Haas, \& Glick, 1988). In general, higher concordance rates for depressive disorders have been reported among monozygotic (MZ) twins relative to dizygotic (DZ) twins (Tsuang \& Farone, 1990). In fact, MZ twins are approximately three times more likely to develop a depressive disorder than are DZ twins (Clarkin et al., 1988). Because twins not only share the same genes but also the same psychosocial environment, studies of twins who grew up together versus those who grew up in separate environments can help illuminate the role that genetic and environmental variables play in the development of depressive disorders. In one such study, a concordance rate of $(67 \%)$ was found for MZ twins who were reared apart (Price, 1968).

Another method for studying the genetic contribution is to compare the rates of depressive disorders in first-degree relatives who share $50 \%$ of their genes including parents, children, and siblings, to second-degree relatives who have $25 \%$ of their genes in common including grandparents, aunts, uncles, nieces, and nephews. A considerably higher rate of depressive disorders has been found among firstdegree relatives of depressed probands relative to the general population (Gershon, Hamovit et al., 1982). In fact, children with a depressed parent have a $15 \%$ risk of developing a depressive disorder, which is six times greater than for children with nondepressed parents (Downey \& Coyne, 1990). Furthermore, if both parents have a depressive disor- 
der, the child's chances increase to $40 \%$ (Goodwin, 1982). Interestingly, children who have second-degree relatives with a depressive disorder are not at any greater risk for developing a depressive disorder than anyone else in the general population (Tsuang \& Farone, 1990). Although the results of these studies provide support for the genetic link to depressive disorders in children, these findings are confounded by the sharing of a common family environment in the studies of first-degree relatives. Adoption studies can, to some extent, shed additional light on the contribution of genetic and environmental factors.

Mendlewicz and Rainer (1977) conducted a study using individuals who were adopted as infants and developed a depressive disorder. A depressive disorder was found in $31 \%$ of the subject's biological parents versus $12 \%$ in adoptive parents. Because the concordance rate is higher among biological as compared to adoptive parents, the results once again suggest that there is a genetic link to depression.

\section{Psychosocial Influences}

While it is generally recognized that the family plays an influential role in the psychological and psychosocial adjustment of children, little relevant research has been conducted with families of depressed youths. Evidence from clinical observations and research indicates that many depressed youngsters come from disturbed families (for reviews see Burdach \& Borduin; 1986: Stark \& Brookman, 1992). Early reports provided evidence for the existence of disturbances within the families of depressed youths, but they did not identify the specific nature of the disturbances. For example, Kaslow, Rehm, and Siegel (1984) reported greater general dysfunction among the families of children who had elevated scores on the CDI (Kovacs, 1981), relative to normal controls. Asarnow and colleagues (1987) also reported disturbances in the perceived family environments of depressed children, but these disturbances were nonspecific to psychopathology. Additional research suggests that the families of depressed youths are characterized by greater chaos, abuse and neglect (Kashani, Ray, \& Carlson, 1984), conflict (Forehand, Brody, Slotkin, Fauber, McCombs, \& Long, 1988), a critical, punitive and belittling or shaming parenting style (e.g., Arieti \& Bemporad, 1980; Poznanski \& Zrull, 1970), communication difficulties (Puig-Antich, Lukens, Davies, Goetz, Brennan-Quattrock, \& Todak, 1985), lower activity level (Puig-Antich et al., 1985), structural disturbances (Grossman, Poznanski, \& Banegas, 1983), and when affection is expressed, it is contingent upon behavior that is consistent with parental expectations (Grossman et al., 1983). In addition, the tone of the mother-child, and to a somewhat lesser extent the fatherchild relationship, was characterized as cold, hostile, tense, and at times rejecting (Puig-Antich et al., 1985) In one of our own studies, an attempt was made to evaluate mothers' and depressed children's perceptions of their family milieu using a measure that assessed a breadth of characteristics of family functioning (Stark, Humphrey, Crook, \& Lewis, 1990). Results of the investigation of the family milieu indicate that there appears to be a unique pattern of disturbances in the families of depressed, anxious, and comorbid depressed anxious children. The diagnostic groups of the children could be accurately predicted based on the children's and parents' perceptions of family functioning.

\section{Implications and Treatment Issues}

Depressed youngsters appear to be placed at risk for the development of a depressive disorder by a genetic diathesis (Clarkin et al., 1988). This diathesis may be triggered by stressors within the youngster's family environment including elevated levels of conflict (Forehand et al., 1988), critical and punitive parents (Arieti \& Bemporad, 1980), decreased involvement in social and recreational activities, low levels of support, and limited involvement of the children in decisions made within the family (Stark et al., 1990). From existing research it is not evident to what extent these environmental disturbances precede the child's depressive disorder and to what extent they result from the depressive disorder. The sources of conflict have not been identified. It is possible that the conflict is between the marital partners, a parent and the depressed child, the depressed child and siblings, or some other combination of family members. While clinical observations indicate that parents of depressed youngsters use critical and punitive parenting techniques, research has yet to validate this observation and to elucidate the specific behavior. The failure of the family to participate in pleasant activities may stem from a variety of factors, possibly including family conflict and punitive parenting tactics. Regardless, it is apparent that a family intervention component is necessary. This intervention should be directed toward reducing conflict that may involve the entire family, or it may include the treatment of a depressed parent.

\section{Psychophysiology and Depression}

The notion that depressive disorders are the result of a combination of a biologically based diathesis and psychosocial stressors is gaining greater acceptance (Preston \& Johnson, 1993; Venzke, Farnum, \& Kremer, 1987). Psychophysiological variables have been widely researched in depressed adults and are now being explored in depressed children (Burke \& Puig-Antich, 1990). This research has progressed from the assumption that biological factors and characteristics of depression are the same in children, adolescents, and adults, to the recognition that developmental differences exist. Many of the biological characteristics exhibited by children differ from those of adolescents, and adolescent characteristics differ from those of adults. Furthermore, differences have been found between pre- and postpubertal cases suggesting that particular physiological traits associated with depression have both a developmental and a neuromaturational basis (Riddle \& Cho, 1988). Re- 
searchers have delineated several psychophysiological variables that may be implicated in childhood depressive disorders (Burke \& Puig-Antich, 1990; Kalat, 1992; Shelton, Hollon, Purdon, \& Loosen, 1991) including neurotransmitter and neuroendocrine dysfunction (cf. Fristad, Weller, Weller, Teare, \& Preskorn, 1988), irregularities in normal biological rhythms, and hormonal changes (Burke \& PuigAntich, 1990).

Results of this research suggest that it is sound practice to encourage the child's parents to obtain a complete medical evaluation for the child from a psychiatrist to determine whether a medical condition could be producing the depressive symptoms (e.g., thyroid disorder), and to determine whether it is medically safe for the child to take an antidepressant. If so, while there is not unequivocal support for the efficacy of antidepressants, a trial of antidepressant medication may prove helpful for alleviating depressive symptoms.

\section{Integrated Model}

As noted in previous sections, there is empirical support for the association of cognitive, behavioral, family, and biochemical variables with depression during childhood. Most of the existing research evaluates the association between one of these domains to depression. No research has explored the possible concurrent and relative contribution of these variables to depression in children. One study was designed to identify which cognitive, behavioral, and family variables, from among those associated with the predominant models of depression, would differentiate depressed from anxious and normal control children (Stark, Humphrey, Laurent, Livingston, \& Christopher, 1993). Results of this study have implications for a model of childhood depression and for the treatment model that is proposed in a later section of this article.

We hypothesized that variables from each of the cognitive, behavioral, and family domains would contribute to the differentiation of the groups and that a measure that assessed the child's sense of self would, relatively speaking, account for most of the between group variance. Based on the existing research, we predicted that less appropriate social skills and more inappropriate assertiveness would characterize the depressed subjects, and that the youngsters' depression would be supported by maladaptive messages about the self, world, and future from parents and by a dysfunctional family environment.

Results indicated that a combination of seven variables from the cognitive, behavioral, and family domains contributed more to the differentiation of the diagnostic groups than the variables from any single domain, and that the different disorders were characterized by different self-reported cognitions. In general, children who had a depressive disorder reported more negative cognitions than did anxious or control children. Within the behavioral domain, the children's ratings of the degree to which they exhibited impulsive and angry social behaviors differentiated the clinical groups. Four variables from the family domain, including the children's perceptions of the messages that they receive about themselves, their world, and their future from their mothers and fathers, the quality of the relationships that they have with other family members, and the parents' style of managing their families all added to predictive ability.

\section{Clinical Significance}

In this section, results of the previously cited research are integrated into a possible model of depression in children. It is believed that, in addition to the mood disturbance, depression is associated with disturbances in all four domains (cognitive, behavioral, familial, and physiological) and that a reciprocal relationship exists between the domains. Thus, a disturbance in one domain would affect, and be affected by, each of the other domains. For example, a biochemical disturbance would affect the youngster's information processing and mood. These disturbances would feedback to, and impact the biochemical disturbance and they would affect the youngster's behavior which in turn impacts the environment. Reactions of significant others in the environment may be misperceived which leads to a confirmation of, or development of, dysfunctional schemata. Once activated, these dysfunctional schemata guide information processing. It has been hypothesized (e.g., Beck et al., 1979; Cole \& Turner, 1993), and research is beginning to appear which supports the notion that the core schemata are formed through early learning experiences and communications within the family (Stark et al., in press-b). In the case of the depressed youngster, negative views of the self, world, and future may develop as a result of negative evaluative statements directed at the child from the parents (Stark et al., in press-b), from interactions that communicate rejection (Puig-Antich et al., 1985), and an over-reliance on punitive parenting procedures (Poznanski \& Zrull, 1970) which once again communicate to the child that he or she is "bad" and the world is an unpleasant place. It is important to note that the child, through genetic predispositions and temperament factors, plays a role in constructing this environment.

It is within the family milieu that the child develops crucial interpersonal skills. In the case of the depressive family milieu, the child learns a more impulsive and angry style of interacting and one in which rejection is expected (Stark et al., 1990). As the child develops, he or she begins to interact with others and these interactions are both shaped by, and shape, existing social skills as well as the youngster's schemata about social situations. The depressed youngster behaves in an impulsive and angry style (Stark et al., in press-a), which leads to rejection. This rejection in turn leads to the development of a sense of self, which is composed of a poorly developed positive self-schema and a more active negative self-schema (Prieto et al., 1992) and negative world schemata (Kaslow et al., 1992). In addition, it may lead to withdrawal (Kazdin et al., 1985), which insulates the young- 
ster from corrective learning experiences. As the youngster matures and faces new stressors, he or she does not have the family (Stark et al., 1990) or peer social support (Blechman et al., 1986; Jacobsen et al., 1983; Kennedy et al., 1989; Peterson et al., 1985) necessary to help buffer their impact, and the impact is further heightened through negative distortions in information processing (Kendall et al., 1990) and a possible deficit in coping skills. Affect interacts with the previously mentioned variables in a reciprocal fashion. The youngster may experience dysphoria due to the perception of social or familial rejection, from the conflictual and punitive atmosphere within the family milieu (Forehand et al., 1988), or from biochemical imbalances. Similarly, the mood disturbance impacts the youngster's information processing and behavior. While this model is speculative, research provides supportive evidence for the reciprocal interplay of three of the major domains of inquiry, and has done so with children (Stark et al., in press-b).

Results of this research have implications for the treatment of children with depressive disorders. It is apparent that the intervention should be a multifaceted one that includes family intervention, parent training, and interventions directed at the child. The family intervention should include the identification of verbal and behavioral interactions that send maladaptive, schema-consistent messages to the depressed child (Stark et al., 1993).

In other words, the therapeutic question becomes, what are parents and/or other family members communicating to the child verbally and/or through their interactions that would lead to the development and maintenance of the child's negative view of the self, world, and future, and other maladaptive schemata. Once the maladaptive interactions are identified, the therapist works with the family to change them. This may take any of many forms dependent on the therapist's training. From a cognitive-behavioral perspective, it may involve cognitive restructuring procedures to change the beliefs that underlie the participants' behavior, and teaching family members new ways of interacting through education, modeling, rehearsal, coaching, and feedback. Subsequently, a parent would be assigned the homework task of self-monitoring the occurrence of the maladaptive interactions as well as engagement in more adaptive interactions.

When working with the family, it is important to determine whether conflict exists (Forehand et al., 1988), and if so, its source must be identified and plans developed for reducing it. The plans may include marital counseling (Kaslow et al., 1984). Because a reduced rate of involvement in recreational activities was reported (Stark et al., 1990), it may prove useful to include scheduling of pleasant activities into family therapy. Caution would have to be taken when doing this, because it could create more opportunities for family conflict. Reduction in conflict and engagement in more pleasant activities as a family could enhance the family's sense of cohesion. Research also suggests the impor- tance of promoting inclusion of children in some of the important decisions being made by the family (Stark et al., 1990). However, a balance needs to be struck between encouraging children to participate in decision making and maintaining a sense of the parents functioning as the executive pair who are in charge (Grossman et al., 1983).

Results suggest that depression in children is associated with a distortion in self-evaluation rather than a deficiency in information processing (Kendall et al., 1990), which further suggests that an efficacious intervention would be one that teaches depressed children to identify their maladaptive cognitions and modify them or replace them with more adaptive ones. This cognitive restructuring can be applied to the youngster's maladaptive social schemata (Stark et al., in press-a). In addition, depressed children could benefit from social skills training (Kazdin, 1989; Matson, 1989) accompanied by coping skills training designed to reduce aversive physical arousal. The objective of the social skills training would be to teach the youngsters to behave in a less angry and more pleasant fashion. It would appear that bossiness, stubbornness, frequent complaining, and expressions of anger and jealousy are potential targets for intervention. Cognitive restructuring interventions should be integrated with the skills training to simultaneously increase engagement in social interactions, reduce negative expectations, negative self-evaluations, and other negative cognitions, and to increase coping self-statements. Additionally, since the comorbid depressed-anxious children reported thinking that others were "picking on them," perhaps reflecting the encoding disturbances noted by Prieto et al. (1992), the children may need to be taught to more accurately monitor, perceive, and evaluate the behaviors and intentions of others. The children noted that they were quick to anger, felt jealous, became angry when someone else was successful, and felt lonely (Stark et al., in press-a), suggesting that cognitive interventions and affective education (Stark, 1990) could be used to impact the affective nature of the disturbance. Furthermore, these interventions may need to teach children how to monitor their own expression of angry and irritable behavior, as well as encourage the children to engage in more appropriate behavior. Relaxation training could be incorporated into the treatment to help the youngsters cope with and minimize aversive physical arousal.

The results also have broader implications for parent training. Our results (Stark et al., in press-b) argue for the inclusion of a component that teaches parents to be aware of the messages that they are communicating to their children. Basic modules could include teaching parents how to communicate positive and realistic messages to their children about the children themselves, the world, and the future. The training would emphasize teaching parents to use positive behavior management skills, because a positive approach would communicate positive messages about the self, while a punitive approach communicates to the child that he or she is a "bad person." Furthermore, guilt-inducing 
parental behaviors would lead to a sense of self as worthless, bad, and unlovable. Thus, a common theme throughout the parent training would be to teach the parents to ask themselves: "What is the message I am sending to my child about himself or herself through my actions and verbal exchanges?"

\section{Proposed Treatment Model}

\section{Overview}

Based on the previously reviewed research, the child is not the sole target of intervention. The youngster's primary environments and significant others also are targets through parent training, family therapy, and school consultation. Intervention with the parents, family, and school is necessary to support the individual work being completed with the child to encourage the child's use of the coping skills in the extratherapy environment, and to change the environmental events that may be contributing to the development and maintenance of the disturbances.

A combination of individual and group therapy is used to teach the youngsters cognitive, behavioral, and affective coping skills. This dual delivery format appears to be efficacious. Depressed youngsters, due to the very nature of their disturbance, are especially difficult to engage in therapy. The relationship that develops between the youngster and therapist during individual sessions serves as leverage to get the child engaged in treatment and to comply with the treatment regimen including therapeutic homework. In contrast, groups tend to take a longer time to develop a sense of cohesion and a demand characteristic that pushes for treatment compliance. Thus, the therapeutic relationship serves as a motivational bridge until the group begins to develop an identity and motivational properties. If the treatment program is going to be delivered in the most efficacious fashion, which means that core cognitive structures are identified and systematically changed through carefully planned corrective learning experiences (cognitive restructuring), then the therapist must have an empathic understanding of the child's sense of self and the rules (cognitive structures) that guide his or her behavior and processing of information. This depth of understanding often only arises from the intimacy of individual therapy as well as from the opportunity to combine what is learned during individual sessions with information that arises during group therapy and within the family.

Mistrust, especially of peers in a school is a major hurdle to the discussion of personal, potentially embarrassing information within group. Youngsters often hold back such information from the group. Children and most adolescents do not have the introspective abilities of adults and cannot identify themes and rules in their constructions of daily experiences. Thus, the burden for doing this lies with the therapist. Individual therapy typically provides the therapist with more data with which to address this therapeutic objective.
On the other hand, the group therapy format has some advantages. By its very nature, the group provides the therapist with a window into each youngster's social skills and interpersonal relationships. The therapist remains ever vigilant to, and continually assesses, the interpersonal process that is occurring in group and its implications for the interpersonal functioning of each youngster. Once a maladaptive pattern of behavior is recognized, the therapist, and in the best of circumstances, other group members, confront the child with the maladaptive behavior and help the youngster identify his or her thoughts surrounding it. The group helps the youngster develop a plan for preventing the maladaptive

Table 1. Child, Parent, and Family Disturbances Identified through Research and Corresponding Treatments

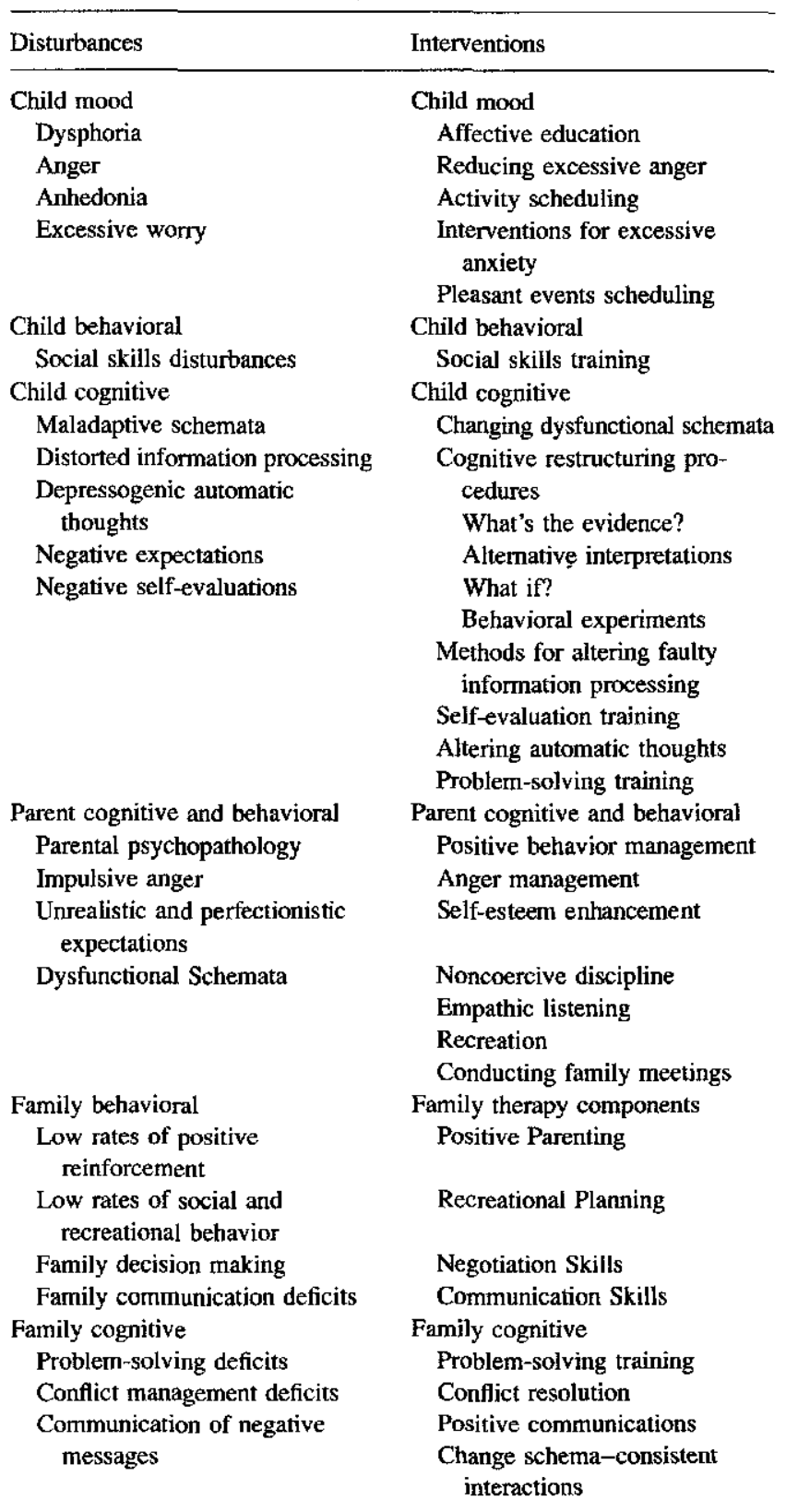


Table 2. Session by Session Outline of Treatment Program

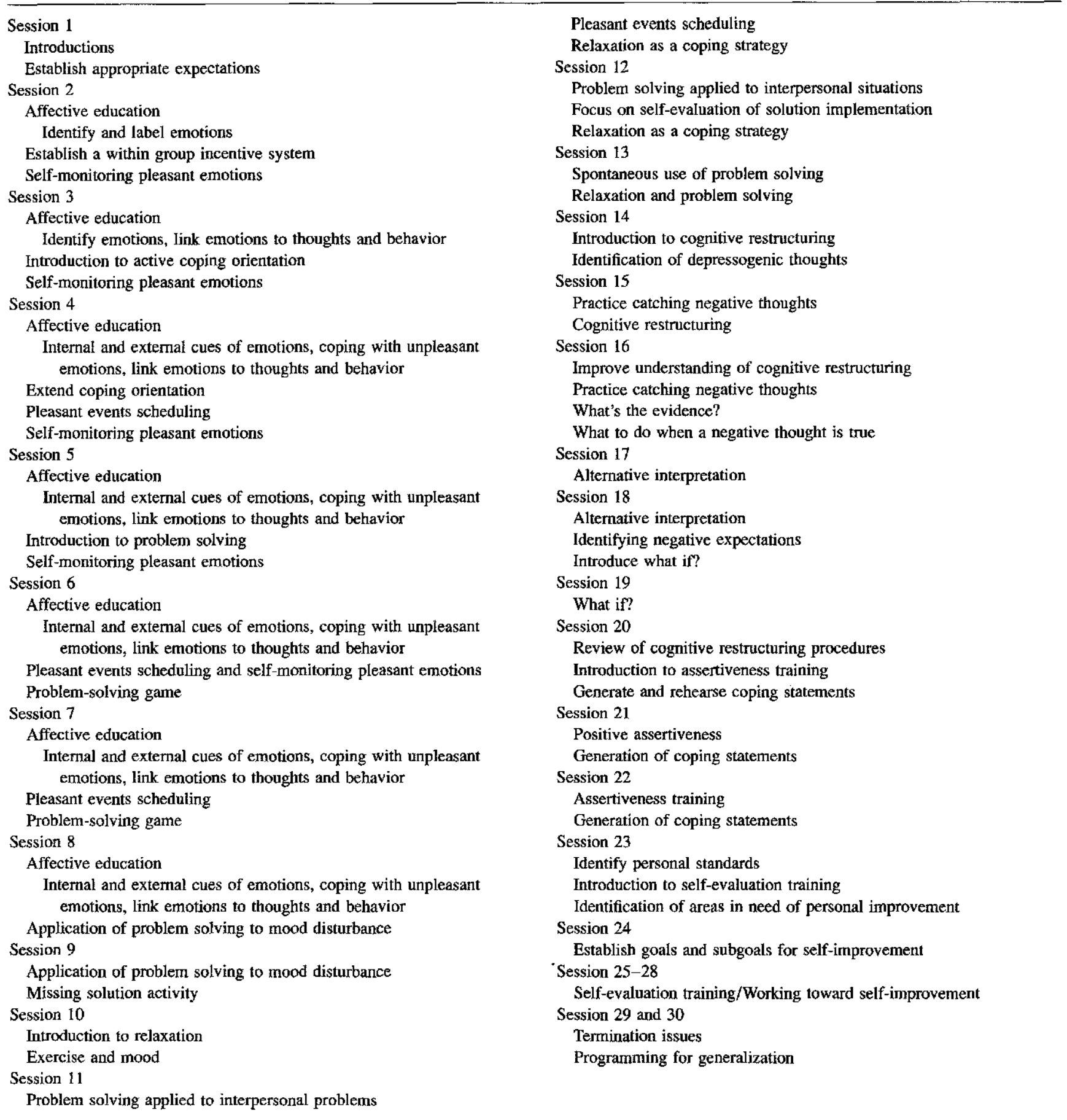

behavior from recurring and for replacing it with a behavior that is more adaptive and yet serves the same function (assuming that the function is a healthy one). The group also provides the therapist with an interpersonal context in which to assess the youngster's social perceptions. This information can be used to provide the youngster with corrective learning experiences both within group and individual therapy. Often this information is used to develop social skill building exercises that are taught and processed in indi- vidual therapy and then practiced within group. Depressed youngsters have negative expectancies and maladaptive thoughts during interpersonal exchanges that inhibit social interactions as well as the implementation of appropriate social behaviors. These thoughts can be restructured during individual therapy and the new thoughts can be tested during group sessions. In a properly running group, the depressed child experiences safety, acceptance, support, and positive feedback which in and of itself leads to some re- 
structuring of negative beliefs about social situations and about the self in a social context. With adolescents and preadolescents, it often is helpful to hear from a peer the same thing that the therapist-an adult-has been saying.

It is difficult with depressed youngsters to establish and maintain a productive therapeutic process during group therapy. Thus, the group meetings tend to be more content focused. In other words, they are focused on skill building rather than relying on the group process to provide therapeutic grist and the medium for change. The content of the groups parallels that in individual therapy (affective education, problem solving, social skills, and cognitive restructuring).

The description of the intervention that follows is organized by type of disturbance to emphasize the parallelism between the disturbances identified in the research and the interventions developed for them. In other words, for each empiricaily identified disturbance, there is a parallel intervention strategy (Table 1). The treatment program may have to be modified dependent on the presence, number, and type of co-occurring disorders. Additional modifications are necessary to address parental psychopathology, a history of abuse, substance abuse, presence of a learning disability, limited intellectual functioning, marital discord, neglect and abandonment, and the presence of features of a developing personality disorder. With all of this said, it also is evident that this presentation may lead the reader to wonder about the logical order of presentation of the various treatment components and how they fit together. Consequently, a prototypic outline of the sequence and integration of the treatment components is provided in Table 2.

\section{Child}

\section{Affective Disturbance}

Emphasis during the first few treatment sessions is on helping the youngsters gain a better understanding of their emotional experiences, teaching them the link between thoughts, feelings, and behaviors, and helping them develop a supportive treatment group. Moreover, recognition of emotions and an understanding of the relationship among thoughts, feelings, and behaviors is the comerstone on which other coping skills are built. To accomplish these as well as additional therapeutic objectives, affective education activities are employed throughout the first eight group meetings.

Depressed youths are experiencing either dysphoria, anger, anhedonia, or a mix of mood disturbances. While some of the intervention strategies specifically target the mood disturbance, it is the authors' belief that ultimately, all of the components have as their goal an improvement in mood. Thus, it is assumed that the mood disturbance will be progressively modified as the youngster begins to cope with the various symptoms of depression and perceives him or herself, life in general, and the future in a more positive and realistic fashion.
Based on a coping skills model, the goal is to teach the youngsters to use their mood as a cue to engage in various coping activities. The first step to this process involves teaching the youngsters a vocabulary for describing their affective experiences. Depressed youths typically do not have an adequate set of labels for the range of their affective experiences (everything is referred to as "bad" or "sad"), or they mislabel them. In addition, they tend to see themselves as either happy or depressed with nothing in between. Thus, the children and their individual therapist collaboratively assess the continuum of emotions that the child experiences. Emphasis is placed on the fact that (1) the child actually experiences a variety of emotions, and (2) each one is experienced along a continuum of intensity from minimal to extreme.

A series of games including Emotional Vocabulary, Emotional Vocabulary II, Emotion Charades, Emotion Statues, Emotion Pictionary, and Emotion Expression is used during group to help the youngsters achieve the aforementioned goals. The games have been described elsewhere (e.g., Stark, 1990). Through participation in these games, the youngsters learn the names of various pleasant and unpleasant emotions and that emotions vary in intensity. In addition, they are better able to recognize when they are experiencing particular emotions and are able to identify them in others. The relationship between emotions, thoughts, and behavior is illustrated through these activities. In addition, strategies for coping with unpleasant emotions and the thoughts that accompany them are identified.

One of the primary tools for altering dysphoric mood is activity scheduling, which is the purposeful scheduling of enjoyable and goal-directed activities into the child's day. Enactment of these activities helps the youngster obtain reinforcement and combat the withdrawal, passivity, and sedentary life-style associated with an episode of depression. They also provide the child with a distraction from his or her preoccupation with negative thinking and lead to some cognitive restructuring as the child sees that life can be enjoyable. During individual therapy, the therapist and child literally schedule pleasant activities for the child on a calendar and solicit parental approval and support for the plan. Within group, the children self-monitor their engagement in pleasant activities, provide each other with encouragement and support for their attempts to become more active, and provide each other with additional ideas about fun things to do. The youngsters contract with the group for an increase in activity level.

It also is important to include in the schedule some mastery activities-activities that have an instrumental value. Completion of the task provides the child with a sense of accomplishment or mastery. For example, completion of a major school project, more homework assignments, a household project, or a hobby kit would lead to a sense of mastery. Within individual therapy, the child and therapist work to combat the child's pessimism and inertia through breaking the project 
down into manageable steps, creating a schedule for completing the steps, and developing coping statements that can be used when the youngster begins to stall or get stuck in negative thinking. Within the group, this same process is taught through completion of a group project.

Excessive anger is a common problem for depressed youths. Teaching children to cope with anger begins with helping them to recognize the sensations that define anger (emotional, cognitive, physical). It is especially important to help children recognize the initial physical and cognitive cues that indicate they are becoming angry. It is critical for children to identify early signs or else they often become overwhelmed with anger too quickly to be able to manage it. Anger is considered to be a cue that a problem needs to be solved. Either the child has to take action to change the anger-provoking situation, or the child has to develop and implement plans for coping with anger. Some of the effective coping strategies are to (a) leave the situation, (b) go and do something enjoyable, (c) use words rather than actions to express anger, (d) do something physically demanding like riding an exercise bike, and (e) expressing anger through drawing or writing. Another useful strategy that is practiced during treatment meetings is to leave a provocative situation as soon as anger is evident and to then listen to a progressive muscle relaxation tape as a means of calming down. Once the child is very skilled at using relaxation, he or she is taught to leave the situation and to direct his or her attention to the muscle tension that is associated with the anger and to focus on relaxing it away. We have found that it is necessary to augment the relaxation training with some self-instructional training and cognitive restructuring that is described in the section on interventions for cognitive disturbances. The cognitive interventions are used to change or counter the youngster's inflammatory thinking.

It is very difficult for a child to follow through and enact one of these coping strategies for managing anger. It usually is necessary for parents to encourage the child to cope by establishing an incentive program. In some instances it also is possible for a parent to cue the child that he or she is becoming angry. This is a sensitive endeavor since telling an angry person that he or she is angry can often escalate the problem. Consequently, a great deal of preplanning and rehearsal are usually necessary. A neutral cueing system typically involving some agreed upon noninflamatory phrase or hand signal can be used to help the youngster without exacerbating the problem.

\section{Problem-Solving Set}

As children appear to be acquiring a better understanding of their emotions, can accurately identify them, recognize their impact on behavior and thinking, and understand that they can take action to moderate the intensity and impact of their emotions, we begin to teach the children to adopt a problem-solving set toward life. They are taught that problems and disappointments are a natural part of life and that when a problem is identified, it is best to actively solve it. In addition, they are taught that their manifestations of depression represent problems to be solved. For example, feeling angry is a cue that a problem exists and that the youngster needs to develop a plan for eliminating the stressor and/or for coping with the feelings. Problem solving also has an impact on the cognitive disturbance. It counteracts rigidity and hopelessness as the youngsters see that there may be some options of which they were previously unaware. The children also gain a sense of self-efficacy as they experience some success and sense of mastery over the environment.

The problem-solving procedure that we have used is a modified version of the one described by Kendall (e.g., Kendall \& Braswell, 1993). Children are taught to break down problem solving into six component steps through education, modeling, coaching, rehearsal, and feedback. Board games are used as an engaging medium for teaching the steps. Games are a fun, concrete method for teaching the process that provides the youngsters with almost immediate feedback in the form of a game-related consequence (e.g., your checker gets jumped) for not following the steps. In addition, the children readily see the advantages to following the process. As they begin to understand each of the six steps and can readily apply them to the games that the group plays, the therapist begins to shift away from game playing within the groups to teaching the youngsters to apply the process to hypothetical problems, to interpersonal problems, and then to problems in daily life.

The first step in the process is problem identification and definition. This may be the most difficult step for children in general to learn. Depressed children often view the existence of a problem as a threat to their self-esteem. If a problem exists, then it means that there is something wrong with them or the problem represents an impending loss. In addition, they feel overwhelmed by problems and feel that they cannot solve them. They also feel that even if they did solve an existing problem, it would simply be replaced by another one. Thus, their sense of hopelessness has to be combated over time through concrete evidence in their life experiences that demonstrates that they can in fact overcome problems. In addition, they may feel too fatigued to try to do anything about their problems. Early in treatment when games are being used, each turn or move represents a problem to be defined and solved. Thus, children get plenty of practice at identifying and defining problems. As treatment progresses, the game format is phased out and children begin to identify their own real-life problems and the problems of other group members.

The second step is getting mentally and emotionally prepared to deal with the problem. The youngsters develop and use coping statements that are designed to help them get motivated for actively dealing with the problem. This step is necessary for the youngsters to complete the problemsolving process. Otherwise they may short-circuit the process by disengaging early after problem identification. 
The third step is generation of alternative solutions. Children are taught to brainstorm as many possible solutions as they can without evaluating them. This is difficult for the depressed youngster because he or she can typically come up with more reasons for why a plan won't work rather than why it would work. Even when they can't identify specific reasons for it not working, they base their prediction on how they are feeling (emotional reasoning). When children are beginning to generate solutions, they often are very limited in the range and number of possibilities. Consequently, they have to be taught additional possibilities. It is important to teach them not to evaluate the alternatives while they are trying to generate them, because depressed youths have a tendency to believe that nothing will work. Thus, the youngster may once again short-circuit the process and generate a minimum of possible solutions. While playing games, the children are taught to consider many possible moves each time their turn comes around. Initially, as they are learning the steps, they are asked to state aloud the possible solutions. This way the therapist and other group members can assist the child in the generation of possible solutions or plans. As treatment progresses and the problems they work on are drawn from real life situations, emphasis is placed on developing solutions that are reasonable, realistic for the context of the adolescent's world, and not just socially acceptable within an adult's world.

The fourth step involves predicting the likely outcomes for each possible solution. Within the context of the games, this involves predicting the outcome of each possible move. As the group progresses into real-life problems, the therapist often has to help the children recognize potential positive outcomes as well as the limitations and self-defeating consequences of other possibilities. Once again, it is necessary at this step to combat the youngster's pessimism. The fifth step involves reviewing the possible solutions, choosing the one that is most consistent with the child's goals and enacting the plan. The final step is evaluating progress toward solving the problem and the outcome of the chosen solution. If the outcome is a desirable one, the child selfreinforces. If the outcome is undesirable, the youngster reconsiders the possible solutions, chooses an alternative one, and enacts it. Once again, coping statements for unsuccessful plans have to be programmed into the treatment.

\section{Maladaptive Behavior}

As mentioned in the discussion of the implications of the research for the treatment of depressed youths, it is necessary to intervene at multiple levels when trying to remediate the disturbance in the depressed youth's interpersonal behavior. To accomplish this most effectively, we also treat this disturbance through a combination of group and individual therapy. Group therapy is used both as a means of continual assessment and as the primary vehicle for teaching the youngsters social skills. Skills are taught through a combination of education, modeling, rehearsal, coaching, and corrective feedback. The children are given weekly homework assignments to try to use their new skills both within group and outside of treatment. As social disturbances become evident during the natural exchanges between group members, those disturbances are directly addressed through feedback from the group and by teaching the youngster more adaptive behavior. The cognitive disturbances associated with the maladaptive behavior are dealt with during individual therapy and the new, more adaptive ways of thinking are tested during group. Similarly, individual sessions and the relationship that develops within them have therapeutic value. The youngster learns how to trust someone and how to deal in a healthy fashion with intimacy. In addition, through the acceptance of the therapist, the youngster learns that he or she is likable and worthy.

\section{Maladaptive Cognitions}

As is evident in Table 2, children are taught various strategies for identifying and altering their maladaptive cognitions. With one exception, these treatment components typically appear late in therapy due to the fact that they require the youngster to become more self-focused, which actually exacerbates depressive symptoms. In fact, the one exception, altering faulty information processing, is included early in treatment because it is designed to redirect the youngster's attention from negative thoughts and feelings to more pleasant emotions and positive thoughts which appears to produce an elevation in mood and energy. In addition, our goal is to provide the youngsters with a base of potential coping skills that they can use to moderate the severity of symptoms prior to directing them to tune into and try to counter or change maladaptive cognitions. It also appears as though the improvement in mood and symptoms in general that results from the other components of the intervention program provide the youngster with some personal distance from their maladaptive thoughts and beliefs, which seems to open them up for change.

It is apparent from the review of relevant research that a treatment program for depressed children should address the disturbances in the youngster's schemata, their processing errors, negative self-evaluations, and hopelessness. Most of the therapeutic work that is designed to change the youngster's maladaptive cognitions is completed during individual sessions. This is not to imply that it is the sole place for using these procedures, as many opportunities arise during group meetings. However, the intensity and intimacy of the individual sessions is better suited for the identification and restructuring of maladaptive thoughts.

\section{Methods for Altering Faulty Information Processing}

Depressed children tend to pay attention to the negative things that are occurring in their lives to the exclusion of the positive. This disturbance may stem from a variety of errors in information processing. To counter this, children can be taught to self-monitor (the purposeful and conscious act of 
observing oneself) positive events and pleasant emotions. This serves as a method for directing the child's attention to more positive things, thus breaking the cycle of negative attention. It helps the children see that there are some positive things going on in their lives. Individualized selfmonitoring assignments or group assignments may be given. A youngster may be taught to observe certain behaviors, thoughts, feelings, or physical reactions and make a judgment about their occurrence or nonoccurrence. In addition, a youngster may be instructed to monitor what is happening when he or she has a specific thought or emotion.

The first step to teaching children to self-monitor is to collaboratively define the phenomena to be observed and to identify examples and nonexamples of it. It is useful to begin the training with a behavior that is likely to occur during the session that gives the therapist an opportunity to help the children tune into the occurrence of the behavior, check for accuracy of self-monitoring, model the procedure if necessary, and reward them for successful and accurate self-monitoring. After identifying and defining the targets for self-monitoring, the children and therapist devise a method for recording these targets. The methods include recording their occurrence or nonoccurrence, how to record, when to record, and how often to record. It is important to devise a system that allows the youngsters to record the occurrence of the target immediately after it occurs. We have created and used emotion diaries. At first, each page in the diary has a series of cartoon characters expressing different pleasant emotions. The youngsters circle the ones they experience each day. As treatment progresses more and more emotions are added and a check sheet is used.

\section{Altering Automatic Thoughts}

The consciousness of depressed children is dominated by negative automatic thoughts. Especially prevalent are negative self-evaluative thoughts. As these thoughts are identified, the cognitive restructuring procedures discussed below along with cognitive modeling and self-instructional training can be used to directly alter them. These automatic thoughts are commonly the target of the therapist through out treatment and the youngsters learn how to identify and modify them on their own later in treatment.

The first step for using either procedure is to make the child aware of his/her tendency to think negatively. This is accomplished through education, thinking aloud while playing games that pull for self-verbalizations (e.g., puzzle building, completing mazes), and helping the child catch negative statements as they occur during the games and other activities during the sessions. It is especially important to watch for signs that the child's mood has changed within the session and then to ask the child to state what he or she was thinking. After catching a negative thought, the youngster is taught to replace it. One method for accomplishing this is for the therapist to model more adaptive thoughts.

Cognitive modeling involves the therapist verbalizing his or her thoughts, or verbalizing more adaptive thoughts that the child might use to replace existing thoughts or ones that he or she might have the next time a particular situation arises. Typically the procedure involves modeling more adaptive thoughts and asking the child to put them into his or her own words and then rehearsing them. In addition to using cognitive modeling when specific thoughts are being targeted, the therapist thinks aloud whenever he or she confronts a problem or some other situation that enables him or her to model adaptive thoughts for the child. This is done throughout treatment as a means of planting seeds of more adaptive thinking.

When a depressed child is having an especially difficult time replacing thoughts, self-instructional training can be used. Self-instructional training (Meichenbaum, 1977) is used to help a child internalize any set of self-statements that guides the child's thinking and/or behavior. In our work with depressed children, we have used Kendall's (e.g., 1977) adaptation of Meichenbaum's procedure. Any content of thoughts can be taught. It is especially useful with children who are experiencing a deficit in their verbal mediational skills, such as a child who simply blows up and exerts no control over his or her emotions.

\section{Changing Dysfunctional Schemata}

One of the ultimate goals of the treatment program is changing the dysfunctional schemata that are hypothesized to give rise to the errors in information processing, depressogenic automatic thoughts, dysfunctional emotions, and behaviors associated with depressive disorders in children. Cognitive restructuring procedures are designed to modify the client's thinking and the premises, assumptions, and attitudes underlying the client's thoughts (Meichenbaum, 1977). The program includes a number of the cognitive restructuring procedures developed by Beck and colleagues (Beck et al., 1979) including (1) What's the evidence?, (2) What's another way to look at it?, (3) What if?, and (4) behavioral experiments. Children are taught to be "Thought Detectives" who identify maladaptive thoughts and (a) evaluate the evidence for the thought, (b) consider alternative interpretations, and/or (c) think about what really would happen if the undesirable event occurred. These procedures are used throughout treatment by the therapist, although the goal is for the children to learn how to independently restructure their negative thoughts. This is accomplished through therapist modeling and the techniques are taught to the youngsters through activities (see Table 2).

Behavioral experiments: Perhaps the most efficient way to change a child's thinking is to strategically alter behaviors that serve as the base of evidence for the child's thoughts. The alteration in behavior and the resultant change in outcomes provide the child with immediate, direct, and concrete contradictory evidence for an existing maladaptive schema or supportive evidence for a new more adaptive schema. This process of assigning personal experiments requires creativity 
as the therapist has to be able to first identify a maladaptive thought or schema, bring it to the child's recognition, work with the child to establish the necessary evidence to support or refute the thought or schema, and then devise a behavioral assignment that directly tests the validity of it. Furthermore, steps have to be taken to ensure that the experiment is actually carried out as planned. In some instances, role playing ahead of time, using imagery to walk through the assignment, or writing a contract may be used to promote compliance. After the experiment has been completed, the therapist works with the child to process the results. This is an important step because the child may distort the results without the therapist's objective input.

\section{Negative Self-Evaluations}

The last portion of treatment is focused on changing the depressed youngster's negative self-evaluations. This occurs last because all of the other self-control and coping skills are brought to bare on the process of working toward and recognizing self-improvement and changing the negative sense of self. Depressed children evaluate their performances, possessions, and personal qualities more negatively than nondepressed youths and their self-evaluations tend to be negatively distorted (Kendall et al., 1990). In other words, they tend to be unrealistically and unreasonably negative in their self-evaluations. Children can be taught to evaluate themselves more reasonably and positively when it is realistic to do so. During this process they learn to recognize their positive attributes, outcomes, and possessions.

The first step of the procedure is to identify the existence and nature of the disturbance. This can be accomplished through the use of the My Standards QuestionnaireRevised (Stark, 1990). This measure allows the therapist to determine whether the child is setting unrealistically stringent standards for his or her performance. Consequently, when the child evaluates his or her performance relative to these standards, the outcome is inadequacy. When this is the case, cognitive restructuring procedures are used to help the child accept more reasonable standards. When the child sets realistic standards, but evaluates him or herself negatively, cognitive restructuring and self-monitoring are used. The cognitive restructuring procedures of "What's the evidence" and cognitive modeling may be used. Self-monitoring would be used as a means of solidifying the new self-evaluations as the child is instructed to self-monitor the evidence that supports it. Over the course of treatment, the therapist and child review the evidence that supports the new selfevaluation. A series of activities have been developed that help the youngsters build a positive sense of self.

In some instances, the child can benefit from change. In such instances, the goal of self-evaluation training becomes helping the child translate personal standards into realistic goals, and then, to develop and carry out a plan for attaining the goals. Following the translation process, the child prioritizes the areas in which he or she is working toward selfimprovement. Initially, a plan is formulated for producing improvement in an area in which success is probable. The long-term goal is broken down into subgoals and problem solving is used to develop a plan that will lead to subgoal and eventually goal attainment. Prior to enacting the plan, the children try to identify possible impediments to carrying out the plan. Once again, problem solving is used to develop contingency plans for overcoming the impediments. Once the plan, including the contingency plans, has been developed, the children self-monitor progress toward change. $\mathrm{Al}$ terations in the plan are made along the way.

\section{School Consultation}

Consultation with school personnel is an important part of the treatment process. Teachers, counselors, and other staff usually are unaware of a depressed youth's difficulties. Because these youngsters rarely cause any problems for their teachers, they basically go unnoticed. This is unfortunate, because their teachers can have a significant impact. From an academic standpoint, the depressed youngster may need to have his or her curriculum altered to be less demanding to fit with the loss of energy, difficulty concentrating, and hopelessness. In addition, due to a variety of insecurities, the depressed youngsters are more dependent on their teachers as they believe that they cannot do their work. Consequently, they need additional support and encouragement rather than condemnation, punishment, or public humiliation.

Teachers are taught to encourage the use of coping skills being taught in individual and group therapy. For example, when the depressed child reports an interpersonal problem, the teacher coaches the youngster through the problemsolving process. In addition, the teacher may use this situation as an opportunity to encourage the child to try out a new social skill. If the youngster is visibly emotionally upset by the situation, the teacher can coach the child through the use of various coping self-statements, relaxation, and distraction techniques.

Teachers often play an important role in the restructuring of the depressed child's thinking. Two of the most common distorted beliefs of depressed youths are (1) No one likes me, and (2) I felt terrible all day. To help the youngsters counter the first belief, when it reflects a distortion, the teacher helps the child to maintain a realistic perspective. A classmate may be upset with the child, but this doesn't mean that he or she hates the child nor does it mean that the peer will remain upset. Perhaps one or two students don't want to be friends with the depressed child. It is important to help the depressed child see that many other classmates do want to be friends.

The easiest way to counter the belief that the whole day was terrible is to instruct the teacher in how to help the child to complete mood ratings at various points during the day. During these one-on-one meetings, the teacher elicits the child's recollections of what transpired that he or she enjoyed since the previous rating. Problem solving is used as a means of helping the youngster develop plans for overcom- 
ing the unpleasant events when they occur. At the end of the day, the child and teacher discretely review and rate the entire day. The discussions focus on what went well during the day. The ratings are then sent home where they are discussed with parents. Teachers also help the youngsters by reminding them to complete various therapeutic homework assignments such as pleasant events schedules, problemsolving diaries, and cognitive restructuring diaries.

\section{Parents}

Parents are seen as a central link between the child's acquisition of skills during therapy sessions and their application to the natural environment. Thus, the parents begin the parent training component at the same time as the child begins therapy. The parent training program is designed to foster a more positive family environment through teaching the parents how to use positive behavior management techniques, reducing conflict, increasing the child's role in the family decision-making process, and by teaching the parents methods for improving their child's self-esteem.

One of the central components of the parent training program is teaching them to use primarily positive behavior management procedures. To accomplish this objective, procedures have been borrowed from Barkley (1987). Initially, the parents are taught to recognize and attend to positive affect and behavior through a series of role play activities. When they can clearly recognize positive behavior as it occurs, can appropriately comment on it, and understand the notion of extinguishing undesirable behavior through nonattention, the parents are assigned the task of spending 1520 min each day playing with their child. They are instructed to make it an enjoyable activity in which they strive to pay particular attention to their child's positive actions. These positive behaviors are socially reinforced and recorded in a diary by the parent throughout the week.

During the next few meetings, parents are taught how to use reinforcement techniques and about the impact reinforcement has on their child's self-esteem. Once again, roleplay activities are used to facilitate acquisition of these skills. Parents collaboratively work with the therapist to identify targets for change and to develop plans to use reinforcement procedures to produce change.

In addition to reinforcement techniques, parents are taught the value of praise. Specifically, praise helps children feel good, boosts self-esteem, and can increase the occurrence of desirable behaviors. Thus, parents are instructed to praise their child a minimum of four to six times per day. Moreover, they are taught to be concrete, genuine, and specific when giving praise. They also are cautioned against using hyperbole and left-handed compliments with their child. During this time, as parents are increasing the use of praise, they are also asked to note how often they criticize their depressed child. The goal of this activity is to eventually reduce the number of criticisms by one each day until they are eliminated.

Parents are then taught how to avoid getting caught in a coercive system. Parents are taught how to give clear and effective directives, the time-out procedure, and the use of natural consequences. Following the training, parents are given an additional homework assignment to monitor their effectiveness in implementing the new disciplinary procedures and to record any problematic situations for consideration at the next meeting.

Observations of some families with depressed children have revealed an especially hostile and angry environment in which parents frequently express their anger in a destructive manner. Such personal verbal attacks on the child shatter self-esteem. Although this tendency to lash out at the child is reduced as a result of the skills taught previously, additional steps are taken to teach the parents to control their own anger. In particular, parents receive instruction in the identification of the triggers of their anger and their underlying thoughts. They are taught to use their anger as a cue to leave the situation, cool off, and then take action. Adaptive coping statements and relaxation techniques are used to combat their angry outbursts. The parents are then asked to apply these skills and to gauge their impact on the family as additional homework.

Some of the difficulties in the relationship between depressed youths and their parents stem from the parent's inability to listen empathically. Through education, parents can learn how to express empathy. A four-step model is used to accomplish this. The first step, active listening, includes avoiding interruptions during the child's communication and providing the child with nonverbal cues that convey undivided attention. Secondly, reflection techniques are taught to parents. These techniques serve the dual purpose of forcing parents to listen to their child and ensuring the child that he or she has been heard correctly. Because some parents tend to editorialize during reflection, avoidance of such remarks is stressed during role plays. The third step in the model consists of helping parents gain an understanding of their child's feelings. The culmination of the training model involves assisting parents in the use of their new skills when interacting with their child. Again, homework is assigned to encourage skill acquisition.

Our previously cited research indicates that families of depressed children often fail to engage in recreational activities. Thus, it is important to teach these families to have fun. Parents are asked to identify various low-cost or nocost activities in which the family can participate. Problem solving is then used to facilitate the scheduling of such activities during the week. In addition to engaging in pleasant activities, parents are instructed to self-monitor the impact of these events on the family.

\section{Family}

Research has associated disturbances in family functioning with depressive disorders in childhood. The therapeutic question becomes, what are the family interaction patterns, verbal and nonverbal communications, and family rules that both lead to and maintain the child's skill deficits and 
cognitive disturbances? Common procedures for altering maladaptive family interactions include education, modeling, rehearsal, communication training, coaching, and feedback. Problem solving and negotiation skills also are used to reduce family conflict.

\section{Conclusions}

The treatment model described in the previous sections was designed to address the cognitive, behavioral, and familial disturbances commonly associated with depressive disorders during childhood. Components of the treatment program have demonstrated utility in previous studies, but the entire package has yet to be evaluated. The state of treatment outcome research in this area in general is inadequate. With a few exceptions, most of the existing research has been conducted with subclinical populations within schools. Thus, the effectiveness of psychosocial treatments for clinic populations is unknown. Given the ever changing nature of psychiatric hospitals, it is likely that the primary location for the treatment of severe psychological disorders in the future is going to be the schools. Thus, school-based models may have greater relevance than once thought. A glaring oversight in the literature is a comparison of the effectiveness of psychosocial, pharmacological, and a combined intervention. Based on clinical experience, some children seem to need the emotional foothold that an antidepres- sant gives them to be able to benefit from the psychosocial interventions. This is especially true for the youngsters who are experiencing anhedonia as their primary mood disturbance. Many additional basic issues remain to be addressed. What is the most effective format for delivering the intervention (e.g. group, individual, combined)? What is the maximally effective time frame? Is there a point where the maximum treatment gain has occurred and additional therapy sessions don't add to the overall effectiveness? As proposed, the child, family, parents, and school personnel are involved in treatment. Is it necessary to involve all of these people? A multicomponent treatment program has been proposed. A disassembly study should be conducted to determine what are the necessary and sufficient treatment components. Is it possible to determine what individual and family characteristics predict treatment success and failure? Perhaps certain strategies work for certain individuals while others don't. What can be done to prevent future episodes of depression? What happens from a psychological standpoint that leads to a relapse? Perhaps of critical importance is studying the process of psychological change. In other words, what intraindividual changes produce a return to a nondepressed state? Similarly, what changes within the family support improvement? It is apparent that much basic research remains to be completed. It is hoped that this article will serve as a catalyst for some of this needed research.

\section{REFERENCES}

Abramson, L. Y., Metalsky, G. I., \& Alloy, L. B. (1989). Hopelessness depression: A theory-based subtype of depression. Psychological Review, 96, 358-372.

Abramson, L. Y., Seligman, M. E. P., \& Teasdale, J. (1978). Leamed helplessness in humans: Critique and reformulation. Journal of Abnormal Psychology, 87, 49-74.

Akiskal, H. S., \& McKinney, W. T. (1975). Overview of recent research in depression: Integration of ten conceptual models into a comprehensive clinical frame. Archives of General Psychiatry, 32, 285-305.

Ambrose, B., \& Rholes, W. (1993). Automatic cognitions and the symptoms of depression and anxiety in children and adolescents: An explanation of the content-specificity hypothesis. Cognitive Therapy and Research, 17(2), 153-171.

Arieti, S., \& Bemporad, J. R. (1980). The psychological organization of depression. American Journal of Psychiatry, 137, 1360-1365.

Asarnow, J. R., \& Bates, S. (1988). Depression in child psychiatric inpatients: Cognitive and attributional patterns. Journal of $\mathrm{Ab}$ normal Child Psychology, 16, 601-615.

Asarnow, J. R., Carlson, G. A., \& Guthrie, D. (1987). Coping strategies, self-perceptions, hopelessness, and perceived family environments in depressed and suicidal children. Journal of Consulting and Clinical Psychology, 55, 361-366.

Bandura, A. (1977). A social learning theory. Englewood Cliffs, NJ: Prentice-Hall.
Barkley, R. A. (1987). Defiant children: A clinician's manual for parent training. New York: Guilford Press.

Baron, R. M., \& Kenny, D. A. (1986). The moderator-mediator variable distinction in social psychological research: Conceptual, strategic, and statistical considerations. Journal of Personality and Social Psychology, 51, 1173-1182.

Beck, A. T. (1967). Depression: Clinical, experimental and theoretical aspects. New York: Hoeber.

Beck, A. T. (1976). Cognitive therapy and the emotional disorders. New York: International Universities Press.

Beck, A. T., Rush, A. J., Shaw, B. F., \& Emery, G. (1979). Cognitive therapy of depression. New York: Guilford Press.

Bedrosian, R. C. (1989). Treating depression and suicidal wishes within the family context. In N. Epstein, S. E. Schlesinger, \& W. Dryden (Eds.), Cognitive-behavioral therapy with families (pp. 292-324). New York: Brunner/Mazel.

Benfield, C. Y., Palmer, D. J., Pfefferbaum, B., \& Stowe, M. L. (1988). A comparison of depressed and nondepressed disturbed children on measures of attributional style, hopelessness, life stress and temperament. Journal of Abnormal Child Psychology, 16, 397-410.

Blechman, E. A., McEnroe, M. J., Carella, E. T., \& Audette, D. P. (1986). Childhood competence and depression. Journal of $A b$ normal Psychology, 95, 223-227.

Burbach, D. J., \& Borduin, C. M. (1986). Parent-child relations 
and the etiology of depression: A review of methods and findings. Clinical Psychology Review, 6, 133-153.

Burke, P., \& Puig-Antich, J. (1990). Psychobiology of childhood depression. In M. Lewis \& S. M. Miller (Eds.), Handbook of developmental psychopathology. Perspectives in developmental psychology (pp. 327-339). New York: Plenum Press.

Butler, L., Miezitis, S., Friedman, R., \& Cole, E. (1980). The effect of two school-based intervention programs on depressive symptoms in preadolescents. American Educational Research Journal, 17, 111-119.

Clarkin, J. F., Haas, G. L., \& Glick, I. D. (1988). Affective disorders and the family: Assessment and treatment. New York: Guilford Press.

Cohen, M. J., Kershner, J., \& Wehrspann, W. (1988). Correlates of competence in a child psychiatric population. Journal of Consulting and Clinical Psychology, 56, 97-103.

Cole, D., \& Turner, J., Jr. (1993). Models of cognitive mediation and moderation in child depression. Journal of Abnormal Psychology, 102, 271-281.

Coyne, J. C. (1976). Toward an interactional description of depression. Psychiatry, 39, 28-40.

Dixon, J. F., \& Ahrens, A. H. (1992). Stress and attributional style as predictors of self-reported depression in children. Cognitive Therapy and Research, 16, 623-634.

Downey, G., \& Coyne, J. C. (1990). Children of depressed parents: An integrative review. Psychological Bulletin, 108, 50-76.

DuPaul, G. J., \& Eckert, T. L. (1994). The effects of social skills curricula: Now you see them, now you don't. School Psychology Quarterly, 9(2), 113-132.

Faust, J., Baum, C. G., \& Forehand, R. (1985). An examination of the association between social relationships and depression in early adolescence. Journal of Applied Developmental Psychology, 6, 291-297.

Fine, S., Forth, A., Gilbert, M., \& Haley, G. (1991). Group therapy for adolescent depressive disorder: A comparison of social skills and therapeutic support. Journal of the American Academy of Child and Adolescent Psychiatry, 30, 79-85.

Forehand, R., Brody, G., Slotkin, J., Fauber, R., McCombs, A., \& Long, N. (1988). Young adolescent and maternal depression: Assessment, interrelations, and predictors. Journal of Consulting and Clinical Psychology, 56, 422-426.

Frame, C., Matson, J. L., Sonis, W. A., Fialkov, M. J., \& Kazdin, A. E. (1982). Behavioral treatment of depression in a prepubertal child. Journal of Behavior Therapy and Experimental Psychiatry, 3, 239-243.

Freeman, A. (1986). Understanding personal, cultural and family schema in psychotherapy. In A. Freeman, N. Epstein, \& K. M. Simon (Eds.) Depression in the family (pp. 79-100). New York: The Haworth Press.

Fristad, M. A., Weller, E. B., Weller, R. A., Teare, M., \& Preskorn, S. H. (1988). Self-report vs. biological markers in assessment of childhood depression. Journal of Affective Disorders, 15, 339-345.

Garber, J. (1992). Cognitive models of depression: A developmental perspective. Psychological Inquiry, 3, 235-240.

Garber, J., Weiss, B., \& Shanley, N. (1993). Cognitions, depressive symptoms, and development in adolescents. Journal of Abnormal Psychology, 102, 47-57.

Garmezy, N., \& Matsen, A. S. (1986). Stress, competence, and resilience: Common frontiers for therapist and psychopathologist. Behavior Therapy, 17, 500-521.
Geller, B., Perel, J. M., Knitter, E. F., Lycaki, H., \& Farooki, Z. Q. (1983). Nortriptyline in major depressive disorder in children: Response, steady-state plasma levels, predictive kinetics, and phamacokinetics. Psychopharmacology Bulletin, 19, 62-65.

Gershon, E. S., Hamovit, J., Guroff, J. J., Dibble, E., Leckman, J. F., Sceery, W., Targum, S. D., Numberger, J. I., Goldin, L. R., \& Bunney, W. E. (1982). A family study of schizoaffective, bipolar I, bipolar II, unipolar, and normal control probands. Archives of General Psychiatry, 39, 1157-1167.

Goodwin, F. (1982). Depression and manic-depressive illness. Bethesda, MD: National Institutes of Health.

Gotlib, I. H., Lewinsohn, P. M., Seeley, J. R., Rohde, P., \& Redner, J. E. (1993). Negative cognitions and attributional style in depressed adolescents: An examination of stability and specificity. Journal of Abnormal Psychology, 102, 607-615.

Gresham, F. M. (1989). Social skills: Conceptual and applied aspects of assessment, training, and social validation. In J. C. Witt, S. M. Elliott, \& F. M. Gresham (Eds.), Handbook of behavior therapy in education (pp. 523-546). New York: Plenum Press.

Grossman, J. A., Poznanski, E. O., \& Banegas, M. E. (1983). Lunch: Time to study family interactions. Journal of Psychosocial Nursing and Mental Health Services, 21, 19-22.

Haley, B. M. T., Fine, S. L., Marriage, K., Moretti, M. M., \& Freeman, R. J. (1985). Cognitive bias and depression in psychiatrically disturbed children and adolescents. Journal of Consulting and Clinical Psychology, 53, 535-537.

Hammen, C. (1991). Depression runs in families: The social context of risk and resilience in children of depressed mothers. New York: Springer-Verlag.

Hammen, C., Adrian, C., \& Hiroto, D. (1988). A longitudinal test of the attributional vulnerability model in children at risk for depression. British Journal of Clinical Psychology, 27, 37-46.

Hammen, C., \& Zupan, B. A. (1984). Self-Schemas, depression, and the processing of personal information in children. Journal of Experimental Child Psychology, 37, 598-608.

Jacobsen, R. H., Lahey, B. B., \& Strauss, C. (1983). Correlates of depressed mood in normal children. Journal of Abnormal Child Psychology, 11, 29-40.

Jaenicke, C., Hammen, C., Zupan, B., Hiroto, D., Gordon, D., Adrian, C., \& Burge, D. (1987). Cognitive vulnerability in children at risk for depression. Journal of Abnormal Child Psychology, 15, 559-572.

Julien, R. M. (1988). A primer of drug reaction (5th ed.). New York: Freeman.

Kalat, J. W. (1992). Biological Psychology. Belmont, CA: Wadsworth.

Kashani, J. H., Ray, J. S., \& Carlson, G. A. (1984). Depression and depressive-like states in preschool-age children in a child development unit. American Journal of Psychiatry, 141, 13971402.

Kashani, J. H., Shekim, W. O., \& Reid, J. C. (1984). Amitriptyline in children with major depressive disorder: A double-blind crossover pilot study. Journal of the American Academy of Child Psychiatry, 23, 348-351.

Kaslow, N. J., Rehm, L. P., \& Siegel, A. W. (1984). Socialcognitive and cognitive correlates of depression in children. Journal of Abnormal Child Psychology, 12, 605-620.

Kaslow, N. J., Stark, K. D., Printz, B., Livingston, R., \& Tsai, Y. (1992). Cognitive Triad Inventory for Children: Development 
and relationship to depression and anxiety. Journal of Clinical Child Psychology, 21, 339-347.

Kaslow, N. J., Tanenbaum, R. L., \& Seligman, M. E. P. (1978). The KASTAN: A children's attributional styles questionnaire. Unpublished manuscript, University of Pennsylvania, Philadelphia.

Kazdin, A. E. (1989). Childhood depression. In E. J. Mash \& R. A. Barkley (Eds.), Treatment of childhood disorders (pp. 135166). New York: Guilford Press.

Kazdin, A. E., Esveldt-Dawson, K., Sherick, R. B., \& Colbus, D. (1985). Assessment of overt behavior and childhood depression among psychiatrically disturbed children. Journal of Consulting and Clinical Psychology, 53, 201-210.

Kazdin, A. E., Rodgers, A., \& Colbus, D. (1986). The Hopelessness Scale for Children: Psychometric characteristics and concurrent validity. Journal of Consulting and Clinical Psychology, 54, 241-245.

Kendall, P. C. (1977). On the efficacious use of verbal selfinstructional procedures with children. Cognitive Therapy and Research, 1, 331-341.

Kendall, P. C., \& Braswell, L. (1993). Cognitive-behavioral therapy for impulsive children. New York: Guilford Press.

Kendall, P. C., Stark, K. D., \& Adam, T. (1990). Cognitive deficit or cognitive distortion in childhood depression. Journal of $A b$ normal Child Psychology, 18, 255-270.

Kennedy, E., Spence, S. H., \& Hensley, R. (1989). An examination of the relationship between childhood depression and social competence amongst primary school children. Journal of Child Psychology and Psychiatry, 30, 561-573.

Kovacs, M. (1981). Rating scales to assess depression in school aged children. Acta Paedopsychiatrica, 46, 305-315.

Kramer, A. D., \& Feiguine, R. J. (1981). Clinical effects of amitriptyline in adolescent depression: A pilot study. Journal of the American Academy of Child Psychiatry, 20, 636-644.

Laurent, J. \& Stark, K. D. (1993). Testing the cognitive contentspecificity hypothesis with anxious and depressed youngsters. Journal of Abnormal Psychology, 102, 226-237.

Lefkowitz, M. M., \& Tesiny, E. P. (1985). Depression in children; Prevalence and correlates. Journal of Consulting and Clinical Psychology, 53, 647-656.

Leitenberg, H., Yost, L. W., \& Carroll-Wilson, M. (1986). Negative cognitive errors in children: Questionnaire development, normative data, and comparisons between children with and without self-reported symptoms of depression, low self-esteem, and evaluation anxiety. Journal of Consulting and Clinical Psychology, 54, 528-536.

Lewinsohn, P. M. (1975). The behavioral study and treatment of depression. In M. Hersen, R. M. Eisler, \& P. M. Miller (Eds.), Progress in behavior modification (Vol. 1, pp. 16-64). New York: Academic Press.

Lewinsohn, P. M., Clark, G. N., Hops, H., \& Andrews, J. (1990). Cognitive-behavioral treatment for depressed adolescents. $\mathrm{Be}$ havior Therapy, 21, 385-401.

Matson, J. L. (1989). Treating depression in children and adolescents. New York: Pergamon Press.

Matson, J. L., \& Ollendick, T. H. (1988). Enhancing children's social skills: Assessment and training. New York: Pergamon Press.

Matson, J. L., Rotatori, A. F., \& Helsel, W. J. (1983). Development of a rating scale to measure social skills in children: The Matson Evaluation of Social Skills with Youngsters (MESSY). Behavioral Research and Therapy, 41, 335-340.
Meichenbaum, D. (1977). Cognitive--behavior modification. New York: Plenum Press.

Mendlewicz, J. \& Rainer, J. D. (1977). Adoption study supporting genetic transmission in manic-depressive illness. Nature, 268, 327-329.

Moilanen, D. L. (1993). Depressive experiences of nonreferred adolescents and young adults: A cognitive-developmental perspective. Journal of Adolescent Research, 8, 311-325.

Mufson, L., Moreau, D., Weissman, M. M., Wickramaratne, P., Martin, J., \& Samoilov, A. (1994). Modification of interpersonal psychotherapy with depressed adolescents (IPT-A): Phase I and II studies. Journal of the American Academy of Child and Adolescent Psychiatry, 33, 695-705.

Mullins, L. L., Peterson, L., Wonderlich, S. A., \& Reaven, N. M. (1986). The influence of depressive symptomatology in children on the social responses and perceptions of adults. Journal of Clinical Child Psychology, 15, 233-240.

Nolen-Hoeksema, S., Girgus, J. S., \& Seligman, M. E. P. (1986). Learned helplessness in children: A longitudinal study of depression, achievement, and explanatory style. Journal of Personality and Social Psychology, 51, 435-442.

Peterson, R. A. (1991). Psychosocial determinants of disorder: Social support, coping and social skills interactions. In P. R. Martin (Ed.), Handbook of behavior therapy and psychological science: An integrative approach (pp. 270-282). New York: Pergamon Press.

Peterson, L., Mullins, L. L., \& Ridley-Johnson, R. (1985). Childhood depression: Peer reactions to depression and life styles. Journal of Abnormal Child Psychology, 13, 597-609.

Petti, T. A., Bornstein, M., Delamater, A., \& Conner, C. K. (1980). Evaluation and multimodality treatment of a depressed prepubertal girl. Journal of the American Academy of Child Psychiatry, 19, 690-702.

Poznanski, E. O. \& Zrull, J. (1970). Childhood depression: Clinical characteristics of overtly depressed children. Archives of General Psychiatry, 23, 8-15.

Preston, J., \& Johnson, J. J. (1993). Clinical Psychopharmacology Made Ridiculously Simple. Miami: Medmaster, 2-13.

Prieto, S. L., Cole, D. A., \& Tageson, C. W. (1992). Depressive self-schemas in clinic and nonclinic children. Cognitive Therapy and Research, 16, 521-534.

Puig-Antich, J., Lukens, E., Davies, M., Goetz, D., BrennanQuattrock, J., \& Todak, G. (1985). Psychosocial functioning in prepubertal major depressive disorders; I. Interpersonal relationships during the depressive episode. Archives of General Psychiatry, 42, 500-507.

Puig-Antich, J., Perel, J. M., Lupatikin, W, Chambers, W. J., Tabrizi, M. A., King, J., Goetz, R., Davies, M., \& Stiller, R. L. (1987). Imipramine in prepubertal major depressive disorder. Archives of General Psychiatry, 44, 81-89.

Puig-Antich, J. H. \& Ryan, N. (1986). Schedule for Affective Disorders and Schizophrenia for School-Age Children. Pittsburgh, PA: Western Psychiatric Institute and Clinic.

Rancurello, M. D. (1985). Clinical applications of antidepressant drugs in childhood behavioral and emotional disorders. Psychiatric Annals, 15, 88-100.

Reynolds, W. M., Anderson, G., \& Bartell, N. (1985). Measuring depression in children: A multimethod assessment investigation. Journal of Abnormal Child Psychology, 13, 513-526.

Reynolds, W. M., \& Coates, K. I. (1986). A comparison of cognitive-behavioral therapy and relaxation training for the 
treatment of depression in adolescents. Journal of Consulting and Clinical Psychology, 54, 653-660.

Rholes, W., Blackwell, J., Jordan, C., \& Walters, C. (1980). A developmental study of learned helplessness. Developmental Psychology, 16, 616-624.

Riddle, M. A., \& Cho, S. C. (1988). Biological aspects of adolescent depression. In G. R. Adams, R. Montemayor, \& T. P. Gullotta (Eds.), Biology of adolescent behavior and development (pp. 223-249). London: Sage.

Robins, D. R., Alessi, N. E., \& Colfer, M. V. (1989). Treatment of adolescents with major depression: Implications of the DST and the melancholic clinical subtype. Journal of Affective Disorders, 17, 99-104.

Ryan, N. D., Puig-Antich, J., Cooper, T. B., Rabinovich, H., Ambrosini, P., Davies, M., King, J., Torres, D., \& Grid, J. (1986). Imipramine in adolescent major depression: Plasma level and clinical response. Acta Psychiatrica Scandinavia, 73, 275-288.

Sacco, W. P., \& Graves, D. J. (1984). Childhood depression, interpersonal problem-solving, and self-ratings of performance. Journal of Clinical Child Psychology, 13, 10-15.

Schwartz, M., Friedman, R., Lindsay, P., \& Narrol, H. (1982). The relationships between conceptual tempo and depression in children. Journal of Consulting and Clinical Psychology, 50, 488490.

Sellstrom, E. A. (1988). Schematic Processing and Self-Reference in Childhood Depression. Unpublished doctoral dissertation. University of Texas.

Seligman, M. E. P., Peterson, C., Kaslow, N. J., Tanenbaum, R. L., Alloy, L. B., \& Abramson, L. Y. (1984). Attributional style and depressive symptoms among children. Journal of Abnormal Psychology, 93, 235-238.

Shelton, R. C., Hollon, S. D., Purdon, S. E., \& Loosen, P. T. (1991). Biological and psychological aspects of depression. Behavior Therapy, 22, 201-228.

Stark, K. D. (1990). The treatment of depression during childhood: A school-based program. New York: Guilford Press.

Stark, K. D., \& Brookman, C. (1992). Childhood depression: Theory and family-school intervention. In M. J. Fine \& C. Carlson (Eds.), Family-school intervention: A systems perspective (pp. 247-271). Massachusetts: Allyn \& Bacon.

Stark, K. D., Humphrey, L. L., Crook, K., \& Lewis, K. (1990). Perceived family environments of depressed and anxious children: Child's and maternal figure's perspectives. Journal of Abnormal Child Psychology, 18, 527-547.
Stark, K., Humphrey, L., Laurent, J., Livingston, R., \& Christopher, J. (1993). Cognitive, behavioral, and family factors in the differentiation of depressive and anxiety disorders during childhood. Journal of Consulting and Clinical Psychology, 61, 878886.

Stark, K. D., Linn, J. D., MacGuire, M., \& Kaslow, N. J. (in pressa). The social functioning of depressed and anxious children: Social skills, social knowledge, automatic thoughts, and physical arousal. Journal of Clinical Child Psychology.

Stark, K. D., Schmidt, K., Joiner, T. E. \& Lux, M. G. (in press-b). Depressive cognitive triad: Relationship to severity of depressive symptoms in children, parents' cognitive triad, and perceived parental messages about the child him or herself, the world, and the future. Journal of Abnormal Child Psychology.

Stark, K. D., Reynolds, W. M., \& Kaslow, N. J. (1987). A comparison of the relative efficacy of self-control therapy and a behavioral problem-solving therapy for depression in children. Journal of Abnormal Child Psychology, 15, 91-113.

Stark, K. D., Rouse, L., \& Livingston, R. (1991). Treatment of depression during childhood and adolescents: Cognitive-behavioral procedures for the individual and family. In P. C. Kendall (Ed.), Child \& adolescent therapy: Cognitive-behavioral procedures (pp. 165-208). New York: Guilford Press.

Strauss, C. C., Forehand, R., Frame, C., \& Smith, K. (1984). Characteristics of children with extreme scores on the Children's Depression Inventory. Journal of Clinical Child Psychology, 16, 235-239.

Tems, C., Stewart, S., Skinner, J., Jr., Hughes, C., Emslie, G. (1993). Cognitive distortions in depressed children and adolescents: Are they state dependent or trait like? Journal of Clinical Child Psychology, 22(3), 316-326.

Tsuang, M. T., \& Farone, S. V. (1990). The Genetics of Mood Disorders. Baltimore: The Johns Hopkins University Press.

Venzke, R. C., Farnum, M. K., \& Kremer, B. J. (1987). Childhood depression: Identifying children and adolescents in need of mental health services. American Mental Health Counselors Association Journal, 9, 28-37.

Young, J. (1991). Cognitive therapy for personality disorders: A schema-focused approach. Sarasota, FL: Professional Resource Exchange, Inc.

Zupan, B. A., Hammen, C., \& Jaenicke, C. (1987). The effects of current mood and prior depressive history on self-schematic processing in children. Journal of Experimental Child Psychology, 43, 149-158. 